\title{
BASIC RADIO PROPAGATION PREDICTIONS FOR NOVEMBER 1945
}

\author{
THREE MONTHS IN ADVANCE
}

ISSUED

AUGUST 1945

PREPARED BY INTERSERVICE RADIO PROPAGATION LABORATORY

National Bureau of Standards

Washington 25, D. C. 
"This document contains information affecting the national defense of the United States within the meaning of the Espionage Act, $50 \mathrm{U}$. S. C. 31 and 32. Its transmission or the revelation of its contents in any manner to an unauthorized person is prohibited by law." 


\section{BASIC RADIO PROPAGATION PREDICTIONS FOR NOVEMBER 1945 THREE MONTHS IN ADVANCE}

The monthly reports of the IRPL-D series are now distributed to the Army as the TB 11-499 series, by the Adjutant General; to the Navy as the DNC-13-1 series, by the Registered Publications Section, Division of Naval Communications; and to others by the IRPI,

This IRPL-D series is a monthly supplement to the IRPL Radio Propagation Handbook, Part 1, issued by the Army as TM 11-499 and by the Navy as DNC-13-1, and is required in order to make practical application of the basic Handbook.'

Comments are invited from user's of this report as to the accuracy of predictions when applied to the solution of specific radio propasation problems. Such comments or queries concerning radio propagation should be addressed as follows:
For the Army:

Headquarters, Army Service Forces,

Office of the Chief Signal Officer,

Washington 25. D. C.

Attention: SPSOL.

For the Navy:

Chief of Naral Operations,

Nary Department,

Washington 25, D. C.

$\left(\mathrm{DNC}-20-\mathrm{F}^{2}\right)$.

For Others:

Interservice Radio Propagation Laboratory,

National Bureau of Standards,

Washington 25, D. C.

\section{CONTENTS}

I. Terminology -

Page 2

II. World-wide prediction charts and their uses- Page 2 World map showing zones covered by prediction charts, and auroral zones Fig. 1

Fo-zero-muf, in IC, $W$ zone, predicted for November 1945

F2-4000-muf, in Me, $W$ zone, predicted for November $1945 \ldots$ Fig. -6

$F$-zero-muf, in Mc, I zone, predicted for Norember 1945

F2-4000-muf, in Me, $I$ zone, predicted for Norember 1945___________ Fig. 8 F2-zero-muf, in Mc, $E$ zone, predicted for November 1945__________ Fig. 9 $F 2-4000-m u f$, in Me, $E$ zone, predicted for November 194.

b-haver 2000-muf, in Mc, predicted for November 1945 Fig. 11

Median $f E s$, Mc, predicted for November 1945

Percentage of time occurrence for $E s$ in excess of $15 \mathrm{Mc}$, predicted for Norember 1945

III Determination of great-circle distances, bearings, location of transmission control points

Great-circle chart, centered on equator - Fig ?

Diagram of transmission path auxiliary to explanation of use of distancebearing monogram, figure 4
III. Determination, etc-Continued.

Nomograin for obtaining great-circle distances, bearings, latitude and longitude of transmission control points. Conversion scale for various distance units.

$1 \mathrm{~V}$. Calculation of maxinum usable frequencies, uptimum working freruencies._._. Page 3

Nomograms for transforming $F^{2}$-zero muf and $72-4000$-muf to equivalent maximum usable frequencies at intermediate transmission distances; conversion scale for obtaining optimum

working frequencies
Nomogram for transforming $E$-layer 2000 muf to equivalent maximum usable frequencies and optimum working frequencies due to combined effect of $E$-layer and F1-layel at other transmission distances

V. Absorption, distance range, and lowest useful high frequency

VI. Sample muf and owf calculations_________- Page 5 For short paths (under $4000 \mathrm{~km}$ ) page 5 , table 1 , page 6 , and figure 16 .

For long paths (over $4000 \mathrm{~km}$ ) page 5, table 2 , page 7 , and figure 17 . 


\section{TERMINOLOGY}

The following symbols are nsed, as recommended by the International Radio Propagation Conference held in Washington, D. C., 17 April to 5 May $19+4$.

$$
\begin{array}{r}
f^{\circ} F 2=\text { ordinary-wave critical frequency } \\
\text { for the } F 2 \text { layer. The term } \\
\text { night } F \text { layer will no longer be } \\
\text { used. The term } F 2 \text { layer is } \\
\text { now used for the night } F \text { as } \\
\text { well as the daytime } F 2 \text { layer. } \\
f^{\prime} F 2=\text { extraordinary-wave critical fre- } \\
\text { quency for the } F 2 \text { layer. } \\
E s=\text { sporadic, or abnormal } E \text {. }
\end{array}
$$

$$
f E s=\text { highest frequency of } E s \text { reflec- }
$$

muf or $\mathrm{MUF}=$ maximum usable frequency.

owf or OWF = optimum working frequency.

t000-muf chart $=$ contour chart of muf for 4000 kilometer paths.

2000-muf chart $=$ contour chart of muf for 2000 kilometer paths.

Zero-muf chart = contour chart of vertical-incidence critical frequency, extraordinary ware.

Note.-The designation $F F_{2}$ has been replaced by $F_{2}$.

\section{WORLD-WIDE PREDICTION CHARTS AND THEIR USES}

The charts, figures 5 to 11 . present world-wide predictions of monthly average maximum usable frequencies for November 1945. Conditions may be markedly different on disturbed days, especially in or near the auroral zones, shown on the map of figure 1. The method of prediction is discussed in the IRPL Radio Propangation Handbook, Part 1, War Dept. TM 11-499, Navy Dept. DNC-13-1, 1). 52,58 .

Although ionosphere characteristics are roughly similar for locations of equal latitude, there is also a considerable variation with longitude, especially in the case of the $F 2$ layer. This "longitude effect" seems to be related to geomagnetic la titude. Attention was first ealled to this effect in the report "Radio Propagation Conditions" issued 10 Sept. 1943 ; it was brought into general operational use in the next issue (14 Oct. 1943).

The longitude effect in the $F 2$ layer is taken care of by providing world charts for three zones, in each of which the ionosphere characteristics are independent of longitude, for practical purposes. These zones are indicated on the world map, figure 1.
Two F2 charts are provided for each zone, one of which, the "zero-muf chart," shows the verticalincidence muf, or the critical frequency for the extraordinary" wave, and the other, the " 4000 muf chart," shows the muf for" a transmission distance of $4000 \mathrm{~km}$. Do not confuse the zero-muf charts with the $f^{\circ} \mathrm{F} 2$ charts appearing in the previous IRPL reports "Radio Propagation Conditions." (Values of $F:$-zero-muf exceed those of $f^{\circ} \mathrm{F} 2$ for the same location and local time by an amount approximately equal to half the gyrofrequency for the location. See IRPL Radio Propagation Handbook, Part 1 (War Dept. TMI 11-499 and Navy Dept. DNC-13-1), p. 18, 19, 28, and fig. 9).

The longitude variation is operationally negligible in the case of the normal $E$ layer and therefore only one $E$-layer chart is provided.

The rariation of $f E s$ with geomagnetic latitude seems to be well marked and important. Consequently, the fEs charts are constructed on the basis of geomagnetic latitude. since there are, as yet, insufficient correlated data, the $f E s$ charts are much less precise than the other charts. Instructions for use of these charts appear in section IV, 3 .

\section{DETERMINATION OF GREAT-CIRCLE DISTANCES, BEARINGS, AND LOCATION OF TRANSMISSION CONTROL POINTS}

\section{BY USE OF THE WORID MAP AND GREAT-CIRCLE CHART}

Figure 1 is a map of the world. Figure 2 is a chart to the sane scale as figure 1 , on which the solid-line curves crossing the equator at a single point represent great circles. The numbered dotdash lines crossing the great circles indicate distances along them in thousands of kilometers. In using figures 1 and 2 proceed as follows: a. Place a piece of transparent paper over the map. figure 1, and draw the equatorial line (zero degrees). Place dots over the locations of the transmitting and receiving stations. Also mark the meridian whose local times are to be used as the times for calculation. Usually the Greenwich meridian is used. 
b. Place this transparency over the chart, figure 2 , and, keeping the equatorial line of the transparency always on the equatorial line of figure 2, slide the transparency horizontally until the terminal points marked on it fall either on the same great circle or the same proportional distance between adjacent great-circle curves. Draw in the path.

c. For paths shorter than $4000 \mathrm{~km}$, locate the midpoint of the path, keeping the transparency in position on figure 2 and using as a distance scale the points at which the numbered lines in figure 2 cross the path as drawn on the transparency.

d. For paths longer than $4000 \mathrm{~km}$, designating the ends as the $A$-end and $B$-end, respectively, locate on the path and mark with a dot the following "eontrol points," sealing the distances as in $c$ allove:

For $F 2$ layer, points $A$ and $B, 2000 \mathrm{~km}$ from each encl.

For $E$ laver, points $A^{\prime}$ and $B^{\prime}, 1000 \mathrm{~km}$ from each end.

\section{BY USE OF THE NOMOGRAM OF FIGURE 4}

In figure $3, Z$ and $S$ are the locations of the transmitting and receiving stations, where $Z$ is the west and $S$ the east end of the path. If a point lies in the Southern Memisphere, its angle of latitude is atways taken as negative. Northern Hemisphere latitudes are taken as positive.

\section{a. To obtain the great-circle distance ZS (short route) :}

(1) Draw a slant line from (lat. $Z$-lat. $S$ ) measured up from the bottom on the left-hand scale to (lat. $Z$ t. lat. $s$ ) measured down from the top on the right-hand scale. If (lat. $Z$-lat. $S$ ) or (lat. $Z+$ lat. $S$ ) is negative, regard it as positive.

(2) Determine the separation in longitude of the stations. Regard as positive. If the angle so obtained is greater than $180^{\circ}$, then subtract from $360^{\circ}$. Measure this angle along the bottom scale, and erect a rertical line to the slant line obtained in $(1)$.

(3) From the intersection of the lines draw a horizontal line to the left-hand scale. This gives $Z S$ in degrees.

(4) Convert the distance ZS to kilometers, miles or nautical miles. by using the scale at the bottom of figure 4.

Note.- The long great-circle route in degrees is simply $360^{\circ}-Z S$. The value will always be gleater than $180^{\circ}$. Therefore in order to obtain the distance in miles from the conversion scale, the value for the dtgrees in exotss of $180^{\circ}$ is added to the value for $180^{\circ}$.

\section{b. To obtain the bearing angle PZS (short mute):}

(1) Subtract the short-route distance $Z S$ in degrees obtained in $a$ from $90^{\circ}$ to get $h$. The value of $h$ may be negative, but will be submitted in (2) below without change of sign.

(2) Draw a slant line from (lat. $Z-h$ ) measured up from the bottom on the left-hand seale to (lat. $Z+h)$ measured down from the top on the right-hand scale. If (lat. $Z-h$ ) or (lat. $Z+h$ ) is negative. regard it as positive.

(3) From $\left(90^{\circ}\right.$ - lat. S) measured up from the bottom on the left-hand scale, draw a horizontal line until it intersects the previous slant line.
(4) From the point of intersection draw a vertical line to the bottom scale. This gives the bearing angle PZS. The angle may be either east or west of north, and must be determined by inspection of a map.

\section{c. To obtain the bearing angle PSZ:}

(1) Repeat steps (1), (2), (3), and (4) in b. interchanging $Z$ and $S$ in all computations. The result obtained is the interior angle $P S Z$, in desrees.

(2) The bearing angle $P S Z$ is $360^{\circ}$ minus the result obtained in (1) (as bearings are customarily given clockwise from due north).

Note.-The long-route bearing angle is simply obtained hy adding $180^{\circ}$ to the short-route value as determined in $b{ }^{\circ} c$ above.

\section{d. To obtain the latitude of? (mid-or other point of path): \\ (This calculation is in principle the converse of 6 .)}

(1) Obtain $Z Q$ in degrees. If $Q$ is the midpoint of the path, $Z$ ? will be equal to one-half $Z, S$. If $Q$ is one of the $2000-\mathrm{km}$ "control points." $Z Q$ will be approximately $18^{\circ}$, or $Z S-18^{\circ}$.

(2) Subtract $Z Q$ from $90^{\circ}$ to get $h^{\prime}$. If $h^{\prime}$ is negative, regard it as positive.

(3) Draw a slant line from (lat. $Z-h^{\prime}$ ) measured up from the bottom on the left-hand scale, to (lat. $Z+h^{\prime}$ ) measured down from the top on the right-hand scale. If (lat. $Z-h^{\prime}$ ) or (lat. $\left.Z+h^{\prime}\right)$ is negative, regarel it as positive.

(4) From the bearing angle $P Z S$ (taken always as less than $180^{\circ}$ ) measured to the right on the buttom scale, draw a vertical line to meet the above slant line.

(5) From this intersection draw a horizontal hine to the left-hand scale.

(i) Subtrace the reading given from $90^{\circ}$ to give the latitude of $Q$. (If the answer is negative then $($ is in the Southern Hemisphere.)

\footnotetext{
NoTE- - If $Q$ is required where $s Q=18^{\circ}$, then werform the above calculation, substituting \& for $\%$. Make sure that the interior angle is used in the calculations. See $c$ above.
} 
e. To obtain the longitude difference $t^{\prime}$ between $Z$ and $Q$ :

(This calculation is in principle the converse of $a$.)

(1) Draw a straight line from (lat. $Z$-lat. $Q$ ) measured up from the bottom on the left-hand scale to (lat. $Z$ +lat. ?) measured down from the top on the right-hand seale. If (lat. $Z$-lat. $Q$ ) or (lat. $Z+$ lat. $Q$ ) is negative, regard it as positive.

(2) From the left-hand side, at $Z Q$, in degrees, draw a horizontal line to the above slant line.

(3) At the intersection drop a rertical line to the bottom scale, which gives $t^{\prime}$ in degrees.

\section{CALCULATION OF MAXIMUM USABLE FREQUENCIES, OPTIMUM WORKING FREQUENCIES}

\section{PROCEDURE FOR DETERMINATION OF MUF AND OWF FOR TRANSMISSION DISTANCES UNDER 4000 KM (PROPAGATION BY THE REGULAR LAYERS)}

a. Prepare or secure work forms similar to IRPL form $A F$ (see table 1 ). Note that form AF provides for the inclusion of sporadic $E(E s)$, which will be discussed under (3) below.

b. Locate the midpoint of the transmission path, using the methods of section III above and by laying the great-circle path transparency back on the work map of figure 1, with the ends of the path in their proper location, determine in which geographical zone, $E, I$, or $W$, the midpoint falls.

c. 'To determine the maximum usable frequency (muf) :

(1) Place the great-circle transuarency over the Fy-zero-muf chart for the proper zone of the midpoint of the path, and, keeping the equatorial line of the transparency over the equatorial line of the chart, slide the transparency horizontally until the Greenwich meridian coincides with 00 on the time scale. Note that all points on the great-circle path are in their proper local time relationship to Greenwich because 24 hours on the time scale of a muf chart is drawn to the same scale as $360^{\circ}$ of longitude on the world map.

(2) Read the value of $F 2$-zero-muf for the midpoint of the path and enter in column $d$ of form AF.

(3) Repeat for 02,04 , ete. on the time scale.

(4) Repeat steps (1), (2), and (3) for the F2-4000-muf chart for the proper zone and again for the $E$-layer 2000-muf chart, figure 11, entering values in columns $e$ and $c$, respectively.

(5) For each hour place a straightedge between the values of $F 2$-zero-muf and $F 2-4000$-muf at the left - and right-hand sides, respectively, of the grid nomogram, figure 13, and read the ralue of the mulf for the actual path length at the intersection woint of the straighted a with the appropriate vertical distance line. Enter in column h. Example:

$F 2$-zero-muf $=6.8 \mathrm{Mc} . \quad F 2$-4000-muf $=23.0 \mathrm{Mc}$

For a distance of $2600 \mathrm{~km}$ the $F^{2}-\mathrm{muf}$ is $19.1 \mathrm{Mc}$.

(6) For each hour place a straightedge between the value of the E-layer 2000-muf on the left-hand scale of the nomogram, figure 14 , and the ralue of the path length on the right-hand scale, and rearl the $E-F 1$-muf for that path length, off the central scale. (Example on nomogram.) Enter in column $g$.

(i) Compare the values of muf obtained by operations (1) to (6). The higher of the two values (columns $g$ and $h$ of form $\mathrm{AF}$ ) thus determined is the muf for the path. Enter in col$11 \mathrm{mn} m$.

d. To determine the optimum working frequency (owf) :

(1) Calculate the $F 2$-owf fiom the $F 2$-muf determined under $e$ above by multiplying by 0.85 or using the conversion scale in figure 13 . Enter in column 7 .

(2) Use for the $E-F 1$-ow the value of $E-F 1$-muf determined under $c,(6)$ above. This represents a change from the previous practice of taking 97 percent of the $E$-F 1 -muf on the nomogram of figure 14. Enter in column $k$.

(3) Compare the F2-owf and E-F1-owf. The higher of the $t$ wo values (columns $t$ and $l$ of form $\Delta F$ ) is that of the path owf. Enter in column n.

\section{PROCEDURE FOR DETERMINATION OF MUF AND OWF FOR TRANSMISSION DISTANCES GREATER THAN $4000 \mathrm{KM}$ (PROPAGATION BY THE REGULAR LAYERS)}

\%. General considerations:

The procedure ontined betow is based on the following assumptions:

(1) That there are Fo-layer control points $A$ and $B$ and $E$-layer control points $A^{\prime}$ and $B^{\prime}$. (See section III. 1, $d$ above.)

(2) That the highest frequency that will "take off" along the path at the $\dot{A}$-end is the highest frequency that can be propagated at $A$ and $A^{\prime}$ considered together.

(3) That the highest frequency that will come in along the path at the $B$-end is the highest frequency that can be propagated at $B$ and $B^{\prime}$ considered towether.

(4) That the highest frequener that can be propagated from the $A$-end to the $B$-end is the lower of the two frequencies of (2) and (3) above. 
(5) 'That the frequency obtained in (4) is the same for propagation from the $B$-end to the A-eml.

b. Frepare or secure work forms similar to IRPL form AH (see table 2 ). Note that form AH provicles for the inclusion of the effects of sporadic $E$ (Es), which wil! be discussed under 3 below.

c. Locate the control points $A$ and $A^{\prime}$ at one end of the path and $B$ and $B^{\prime}$ at the other end of the path as explained under section III, $1, d$ above. For very long paths the "short route" (minor arc of the great-circle path) and the "long route" (major are) need be considered. Placing the transparency back on the world map, determine as in section IV $, 1, b$ above in which geographical zone, $E, I, \mathrm{r}^{*} W$, each of the control points 1 and $B$ falls.

d. To determine the muf:

(1) Place the great-circle transparency over the F2-4000-muf chant for the proper zone of the midpoint of the path for control point $A$ and, keeping the equatorial line of the transparency over the equatorial line of the chart, slide the transparency horizontally until the Greenwich meridian coincides with 00 on the time scale.

(2) Read the value of $F 2$-4000-muf for control point $A$. Enter in column $c$ of form AII.

(3) Repeat for 02,04 etc. on the time seale.

(4) Repeat steps (1). (2), and (3) on the $E$ layer 2000-muf chart, figure 11, using control point $A^{\prime}$. Enter values in column $d$.

(5) Determine the muf for the $A$-end as the higher of the $F 2-4000-$ muf, column $c$, and the $E$ layer 2000-muf, columm $d$. Enter in column $m$.
(6) Read the value of $F 2$-4000-muf for control point $B$, using the F2-4000-muf chart for the proper zone. Enter values in column $i$.

(7) Repeat for 02, 04, etc. on the time seale.

(8) Read the values of $E$-layer 2000 -muf on the E-layer 2000-muf chart, figure 11, using control point $B^{\prime}$. Enter values in column $j$.

(9) Determine the muf for the $B$-end as the higher of the $F 2$-4000-muf column $i$, and the $E$ layer 2000-muf, column $j$. Enter in column $n$.

(10) Compare the two mut values of colums $m$ and $n$. The lower of the two is the muf for the transmission path under consideration. Enter in column $q$.

e. To determine the owf:

(1) Use the scaled data of the previons procedure.

(2) Multiply the F2-4000-muf for the $A$-end, column c, by 0.85 to obtain the $F 2$-4000-owf for the $t$-end, column $f$.

(3) Multiply the F2-4000-muf for the $B$-end, column $i$, by 0.85 to obtain the F2-4000-owf for the P-enk, column ?.

(4) Compare the F2-4000-owf for the $A$-end, column $f$, with the $E$-layer 2000 -muf for the $A$-end, colmmn $\%$. The higher of the two is the ow for the 1 -rind. Enter in column o.

(5) Compare the F2-4000-owf for the $B$-end, column l, with the $E$-layer 2000 -muf for the $B$-end, column $;$. The higher of the two is the owf for the P-end. Enter in columm p.

(6) Compare the two ow values of columus o and $p$. The lower of the two is the owf for the transmission path under consideration. Enter in columm $r$.

\section{PROCEDURES FOR INCLUSION OF THE EFFECTS OF ES}

Sporadic-E (E's) propagation may often allow regular transmission when regular $\dot{E}$ - or $F 2$-layer propagation would not. Es data are not yet sufficient to permit accurate calculations of such propagation, but the $f E s$ charts of figures 12 and 15 are given as a guide to Es occurrence.

As the fEs charts are constructed from considerations of geomagnetic latitude, three latitude scales are provided at the right of the charts of figures 12 and 15 , one for each of the three zones of figure $1(E, I$. and $W)$.

Until further improvements are made. the following procerlures should be used to include the effects of $E s$ in the calculations of muf and owf.

\section{a. For paths over $4000 \mathrm{~km}$ long:}

(1) Place the great-circle path transparency prepared in section III. 1 , over the median $f E$ s chart, figure 12, using the latitude scale for the zone containing the control point.

(2) Scale $f E s$ at control point $L^{\prime}$ and $B^{\prime}$. Enter in columns $a$ and $q$, respectively, on form AfI.

(3) Multiply fEs by 5 in each case, obtaining the Es-2000-muf. Enter in columns $b$ and $h$, respeetively.

(4) In the determination of muf modify the procedure (steps (5) and (9)) of section IV, $2, d$ above to obtain the muf for the $A$ - and $B$-ends, respectively, as the highest of the three items, the F2-4000-muf, the E-layer 2000-muf, and the ES2000-muf. No other change is necessary.

(5) In the determination of owf subtract $4 \mathrm{Mc}$ from the Es-2000-muf to obtain the Es-2000-ow f for the 1 -end and $B$-end, respectively, entering the results in columns $e$ and $k$. Then modify the procedure (steps (4) and $(5)$ ) of section IV, 2 ,e to obtain the owf for the 1 - and $B$-ends, respectively, as the highest of the three items, the F24000-owt, the E-layer 2000-muf. and the Es-2000owf. No other changes are necessary.

b. For paths under $4000 \mathrm{~km}$ long:

(1) Repeat step (1) of a above.

(2) Scale fEs at the midpoint of the path. Enter in column a of form $\mathrm{AF}$.

(3) Multiply fEs by 5, obtaining the ES-2000muf. Enter in columi b. 
(4) In the determination of muf under IV, 1, c. find the Es-muf for the path by use of the same nomogram, figure 14 , as was used for the $E-F 1$ muf. Enter in column $f$. Then modify the procedure in IV, 1, c, (7) so that the higliest of the three values, the $F 2$-muf, the $E-F 1$-minf, and the Es-muf, columns $h, q, f$, is the muf for the path.

(5) In the determination of ow f under IV, $1, d$. subtract $4 \mathrm{Mc}$ from the Es-2000-muf found under (3) above to obtain the Es-2000-owt, entering in colmmn $i$. Now find the $E s$-ow for fhe path, using the same nomogram, figure 14 , as for the $E-F 1$. owf, applying the Es-2000-muf to the left-hand scale and reading the answer on the middle scale. Enter in column \%. Then modify the procedure in section IV, 1, $d$ (3) so that the highest of the three values, the $F 2$-owf, the $E-F 1$-owf, and the $E s$-owf, coimms $7, k, j$, is the ow for the path.

Because of the relative uncertainty with which $E s$ is known. it may often be desirable in shortpath work to operate on a frequency close to owf for the regular layers only, as calculated by the procedure of IV, 1, d, without the inclusion of E.s.

\section{ABSORPTION, DISTANCE RANGE, AND LOWEST USEFUL HIGH FREQUENCY}

The procerlures outlined in the text of this report will give an arlerpuate solution to most of the high-frequency propagation problems that will normally be encomntered in the field. If operating frequencies are chosen near the calculated ow prediction in any given case, best possible results should be had, at least in communications work.

The use of frequencies too far below the owf will result in weak reception beeause of inereasing ionospheric absorption as the frequency decreases. The factor that limits the usefulness of low field intensities is nsually atmospheric noise at the receiving location.
The determination of lowest useful high freqnencies is more difficult than the determination of muf and the techniques for their prediction are less far advanced.

The subject of absorption, distance range, and lowest useful high frequency is discussed at length in IRPL Radio Propagation Handbook, Part 1, p. 69-97 (War Dept. TM 11-499, Navy Dept. INC-13-1), and formulas, graphs, and nomograms for calculation are given there.

Simpler and more acrurate techniques are being developed and will be released as soon as the work is completed.

\section{SAMPLE MUF AND OWF CALCULATIONS}

\section{FOR SHORT PATHS}

Requircel: The muf and owf for transmission between Washington, D. C. $\left(39.0^{\circ} \mathrm{N} .77 .5^{\circ} \mathrm{W}\right)$ and Miami. Fla. $\left(25.7^{\circ}\right.$ N. $\left.80.5^{\circ} \mathrm{W}\right)$ for average conditions during the month of November 1945.

\section{Solution:}

Let the local time used for this problem be GCT ( $Z$ time or that of $\theta^{\circ}$ longitude).

The midpoint of the path is at approximately $32.5^{\circ} \mathrm{N}, 79.0^{\circ} \mathrm{W}$, and the transmission path length is approximately $1500 \mathrm{~km}$, all in $W$ zone.

The values of $E$ - and $F$-layer muf and owf, and also Es-owf for all hours, GC'T, as determined by nsing the procedure given in section IV, are given in table 1. The final values are presenter graphically in figure 16.

Vilues of owf obtained by the procedure of section IV, 1, $e$ for the regular layers only are underscored in columm $l$ of table 1 , and are plotted in figure 16. Values of $E$-owf in colmmm $k$, lid not govern at any hour. Hours in which $E$ s controls transmission are those for which the dotted-line graph for the ow goes above the solid-line graph.
Actually, in this example, 05 is the only hour when this happens. During the other hours the values of owf of column $n$ of form AF coincide with the owf for the regular layers and appear as a solid line.

Figure 16 shows that skip will occur, on the a verage, during the night hours, if a frequency as high as 9.0 Ne is used. A frequency as high as 8.7 Mc will not skip, on the average, at any time of day, but its use is not advisable because of (a) the day-to-day variability, causing some probability of skip during the night homrs, and (b) ionospheric absorption during the daytime, which is more pronounced at low frequencies.

1 satisfactory plan to insure continuous transnimsion at all times, over a path like this, involves the nse of two frequencies, one for night and one for day. Figure 16 shows that a night frequency of 5.2 Me, to be used from 2250 to 1245 GCT, and a day frequency of $11.5 \mathrm{Mc}$, to be used from 1245 to 2250 GCT, would be satisfactory. 'The periods of nsefulness of these frequencies are shown by the heavy dashed line on figure 16.

\section{FOR LONG PATHS}

Required: The muf and ow for transmission hetween Shanghai, (hina $\left(31.2^{\circ} \mathrm{N}, 122.2^{\circ} \mathrm{E}\right)$ and San Francisco, Calif. $\left(37.8^{\circ} \mathrm{N}, 122.4^{\circ} \mathrm{W}\right)$ for avelage conditions during the month of November 1945 .

\section{Solution:}

Let the local time for this problem be GCT ( $Z$ time or that of $0^{\circ}$ longitude).

The path length is approximately $10.000 \mathrm{~km}$, and the two F2-layer control points, $A$ and $B$. re- 
spectively, are at approximately $43^{\circ} \mathrm{N}, 139^{\circ} \mathrm{E}$, and $48^{\circ} \mathrm{N}, 143^{\circ} \mathrm{W}$. These are, respectively, in the $E$ zone and the $I$ zone, as shown on the map, figure 1. 'The two $E$-layer and $E$ 's control points, $A^{\prime}$ 'and $B^{\prime}$, respectively, are located at approximately $37.5^{\circ} \mathrm{N}, 127^{\circ} \mathrm{E}$, and $43^{\circ} \mathrm{N}, 133^{\circ} \mathrm{W}$. The bearing of San Francisco from Shanghai is approximately $45^{\circ}$, and of Shanghai from San Francisco, approximately $310^{\circ}$. both determinet by means of the nomogram of figure 4.

The values of muf and owf over this transmission path, as determined by the procedure in section IV, are given in table 2 for all hours, GCT. The final values are shown graphically in figure 17.

Figure 17 shows that skip will occur, on the average, during the night hours if a frequency as high as $10.0 \mathrm{Mc}$ is used, although higher frequencies may be used during a linited portion of the day.
A good practical arrangement to insure continuous transmission at all times is to select three frequencies, in a manner similar to that suggested in the preceding problem. A frequency of 7.4 Mc may be used from 0500 to $2030 \mathrm{GCT}$, a frequency of 18.0 Mc may be used from 2205 to $0240 \mathrm{GCT}$, and a transition frequency of 9.8 Me may be used from 0240 to 0500 , and from 2030 to 2205 GCT.

By inspection of the absorption chart and the noise map (figs. 90 and 119 of the IRPL Radio Propagation Hantlbook, Part 1, War Dept. TM 11-499, Nary Dept. DNC-13-1), it may be seen that considerations of the lowest useful high frequency over this path may be of considerable importance in selecting frepuencies for use. Consequently, in cases of transmission failure on the frequencies here reconmented, particularly in the case of the transition frequency, changing the frequency to a value slightly under the muf for the path may be advisable. 
$n$

\&

a

$\frac{2}{3}$

9

$\underset{1}{\leftarrow}$

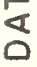

톤

in

山

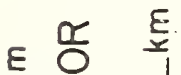

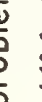

등ㅇㅇ용

in

है⿴囗十)

क

돈

$=E$
$=0$
$\div \quad \frac{\delta}{0}$
$\therefore$

$\div 0$

$\frac{\circ}{\text { जิ }}$

世

등 둥

竞

ஸ

$\therefore 3$

$\frac{1}{4}$

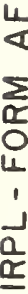

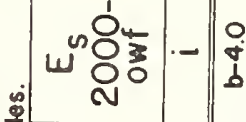
है $u^{1}$

言

穹

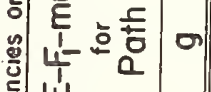

这

w

운

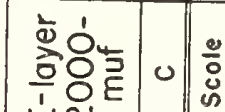

$:$

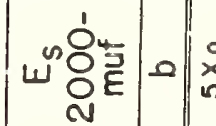

혀

蛴

แ

吉政

है

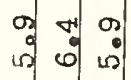
일

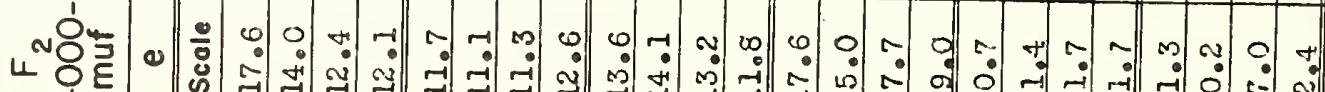

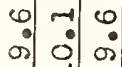

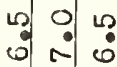

융 과

का मी

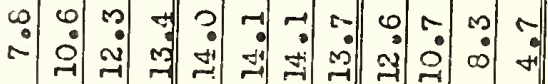

ए

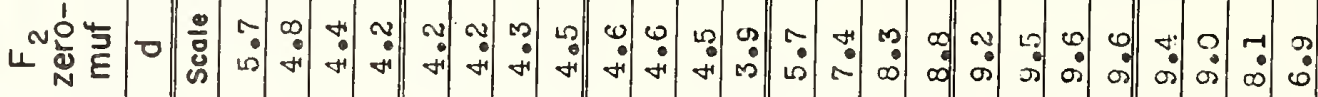

눈

유.

$\infty$ न

กี่

ง.:

空

悹

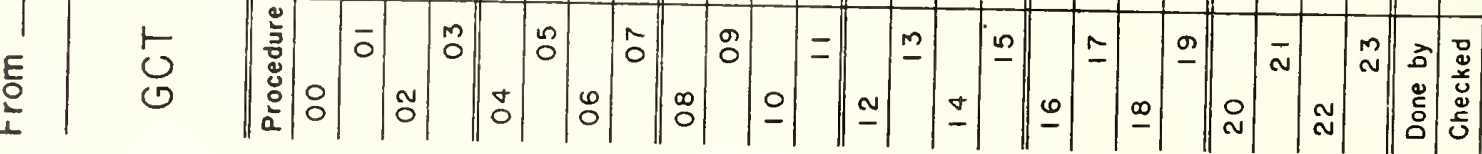

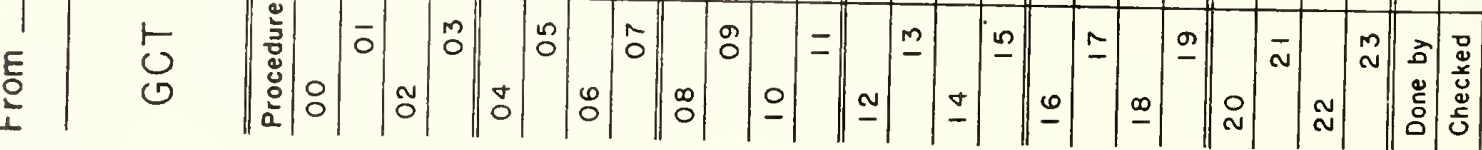




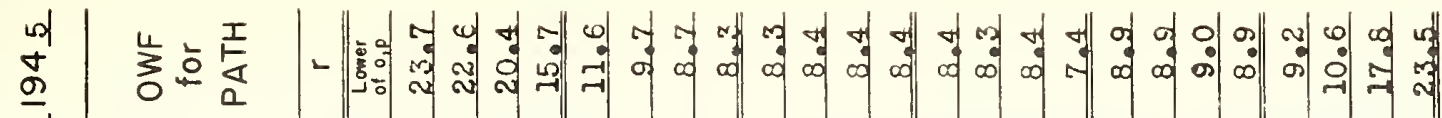
는

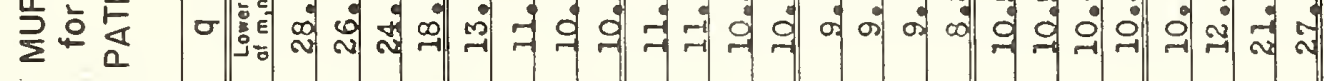

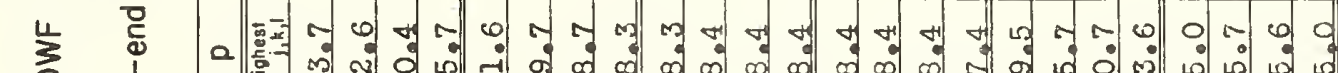

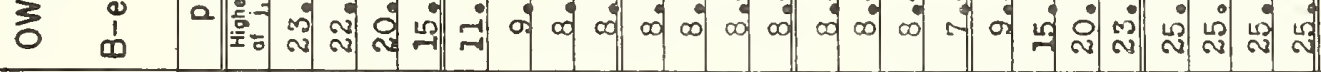

ᄂ

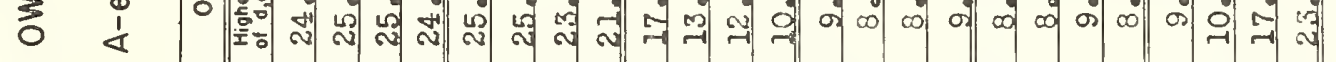
흔

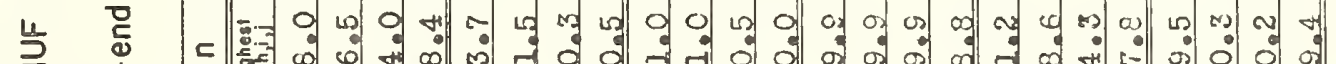

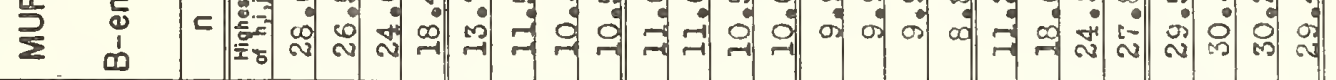

4 D

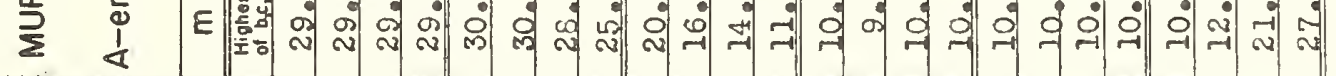

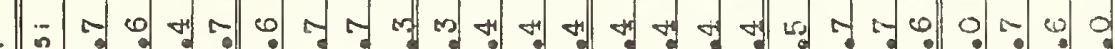

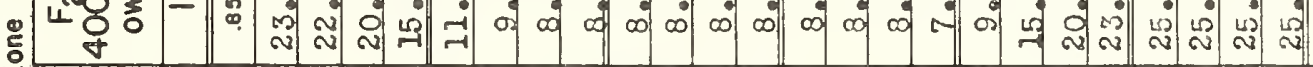

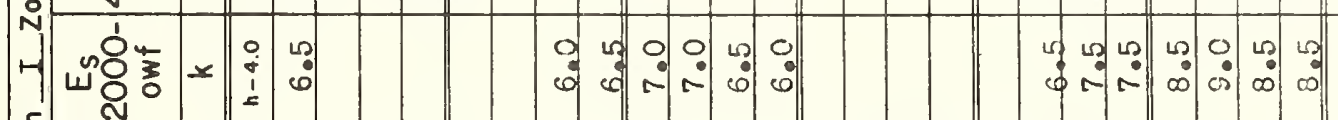
5 i 它家完远 ம. ஸ

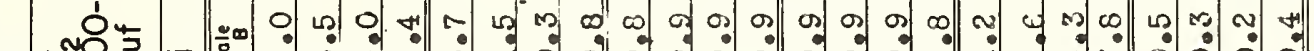
¿ Nó H W

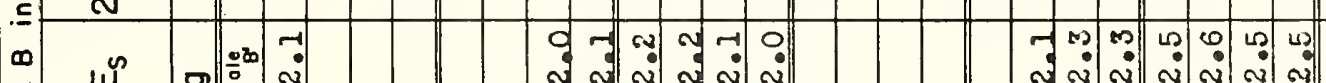

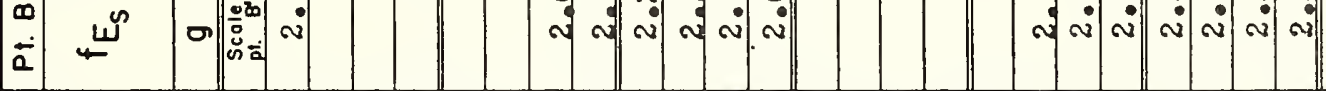

ง

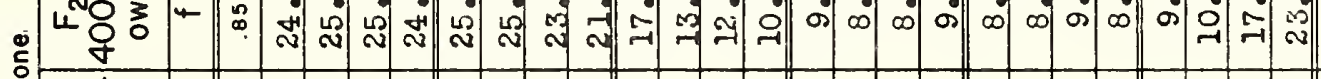

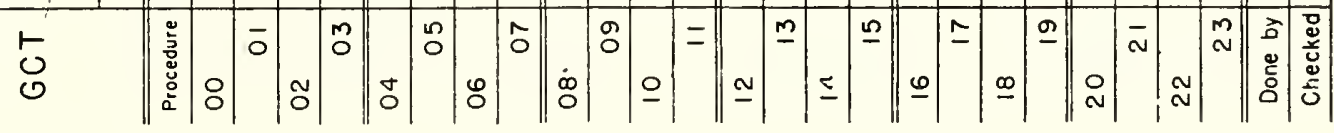




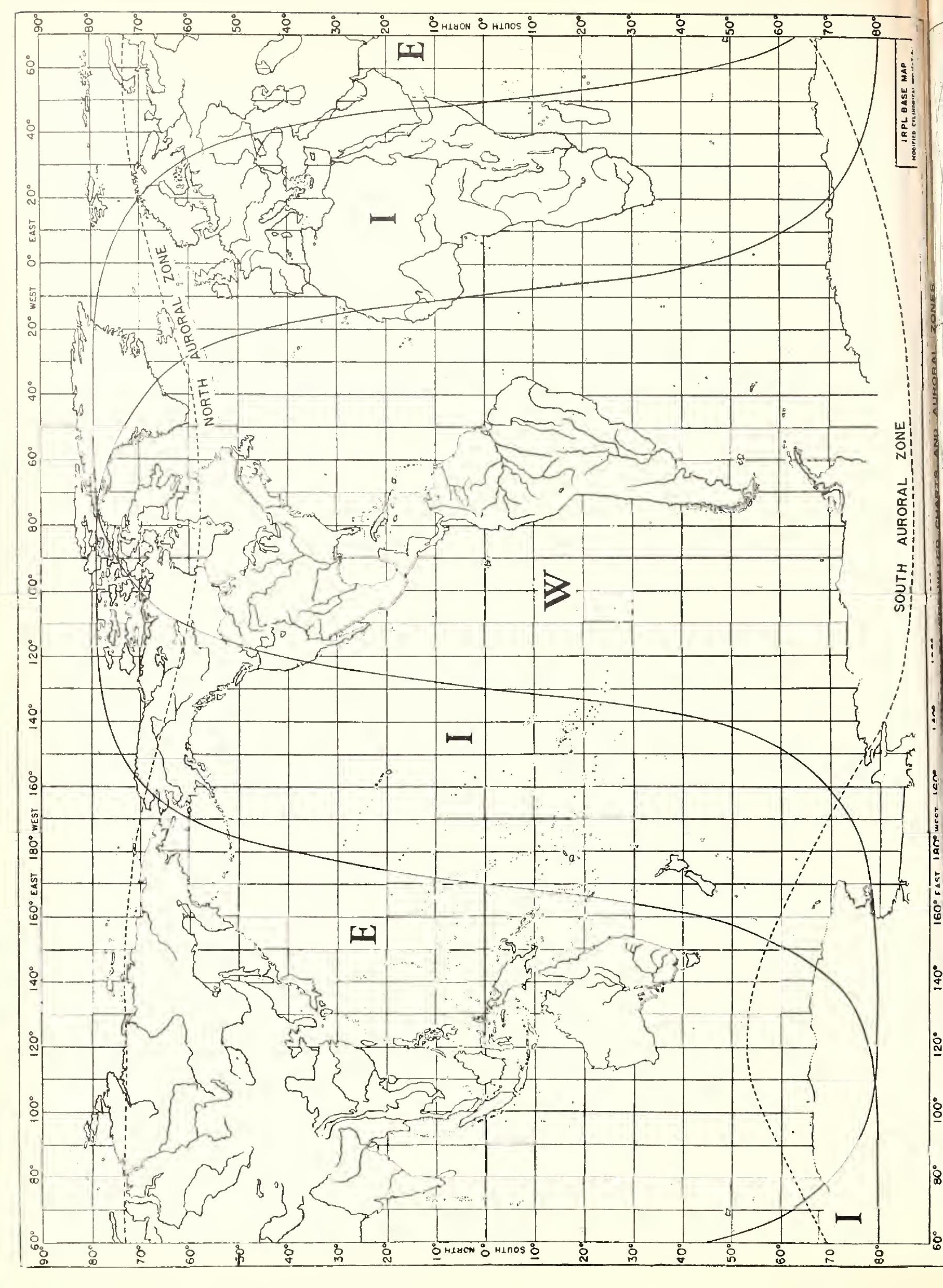




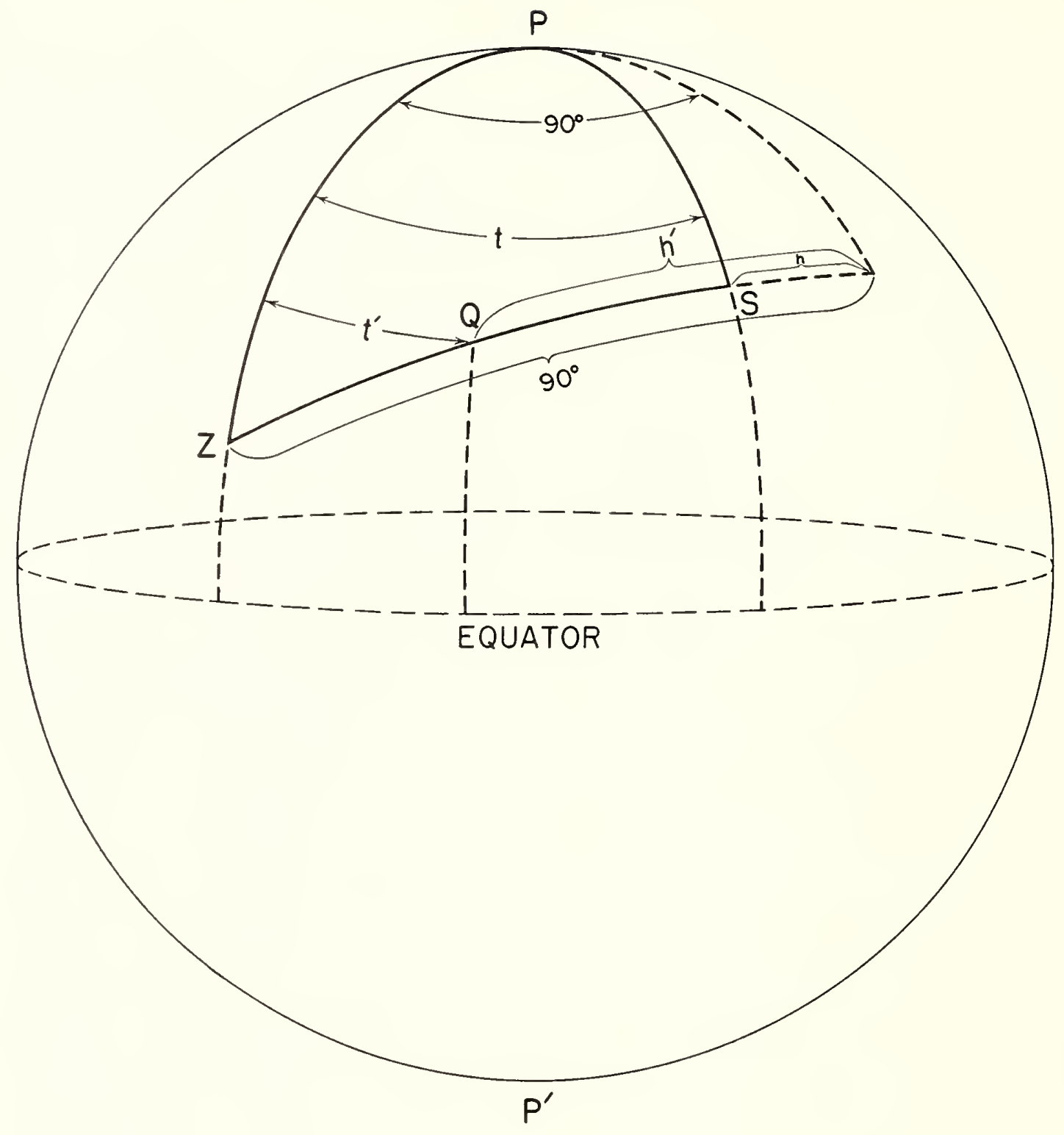

Fig. 3. DIAGRAM OF TRANSMISSION PATH AUXILIARY TO EXPLANATION OF USE OF DISTANCE - BEARING NOMOGRAM, FIG. 4. 


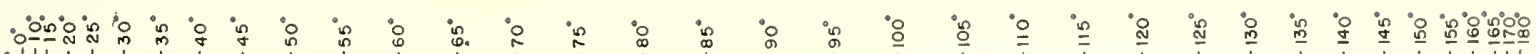
$\begin{aligned} & 180^{\circ}=1 \\ & 170^{\circ} \\ & 160^{\circ} \\ & 150^{\circ} \\ & 15^{\circ} \\ & 145^{\circ}\end{aligned}$
$\begin{aligned} & 140^{\circ}= \\ & 135^{\circ}=\end{aligned}$

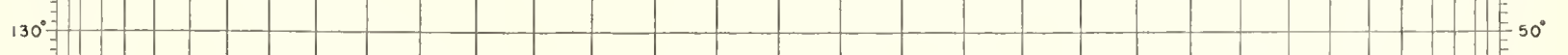

$125^{\circ}=$

$120^{\circ}=$

$115^{\circ}-$

$110^{\circ}-$

$105^{\circ}-1$

$100^{\circ}=$

$95^{\circ}=$

$90^{\circ}=$

$80^{\circ}$

$75^{\circ}$

70

$65^{\circ}$

$60^{\circ}$

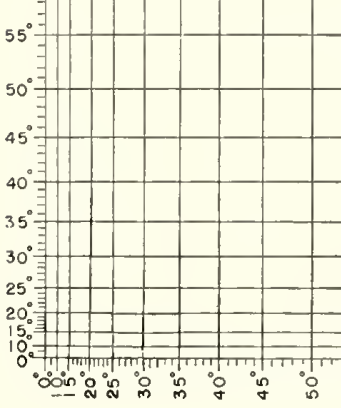

\begin{abstract}
Degrees لر

\begin{tabular}{c}
$\begin{array}{c}\text { Thousonds of } \\
\text { Kitometers }\end{array}$ \\
\hdashline
\end{tabular}

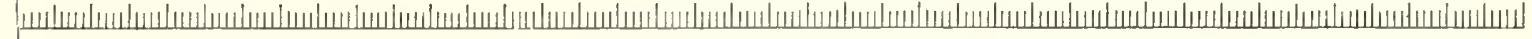

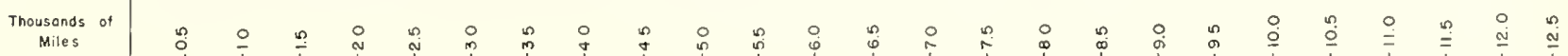

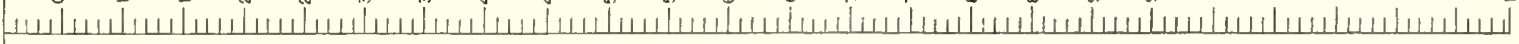
Thousonds of

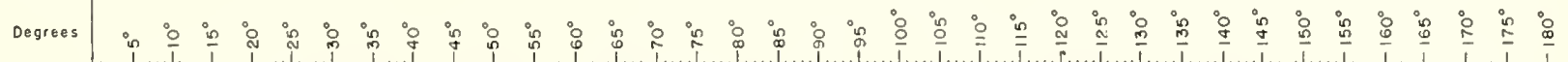

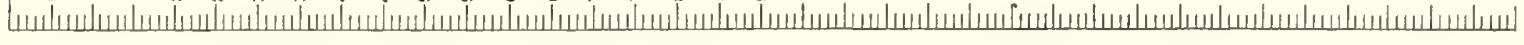

Fig. 4. NOMOGRAM (AFTER D'OCAGNE) FOR OBTAINING GREAT-CIRCLE DISTANCES, BEARINGS, LATITUDE AND LONGITUDE OF TRANSMISSION CONTROL POINTS, SOLAR ZENITH ANGLES. 


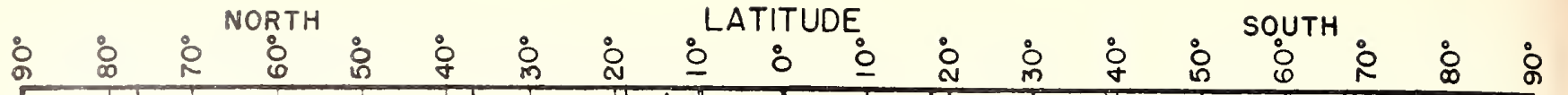

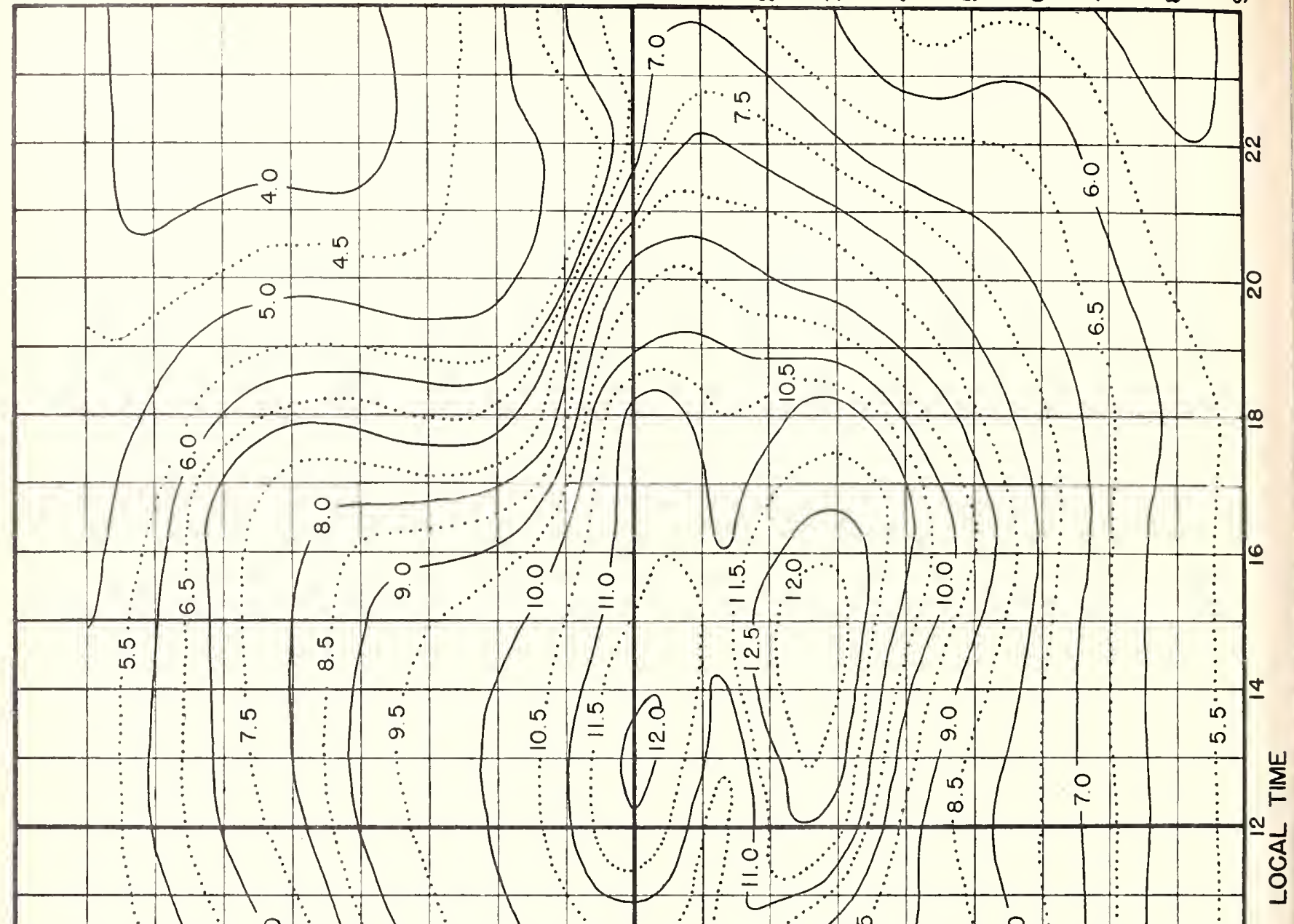

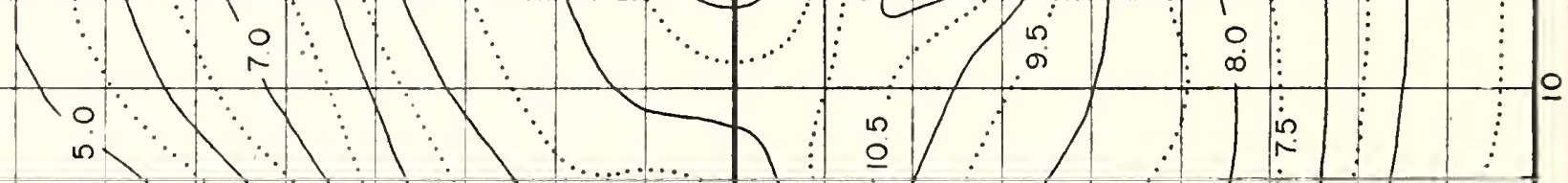
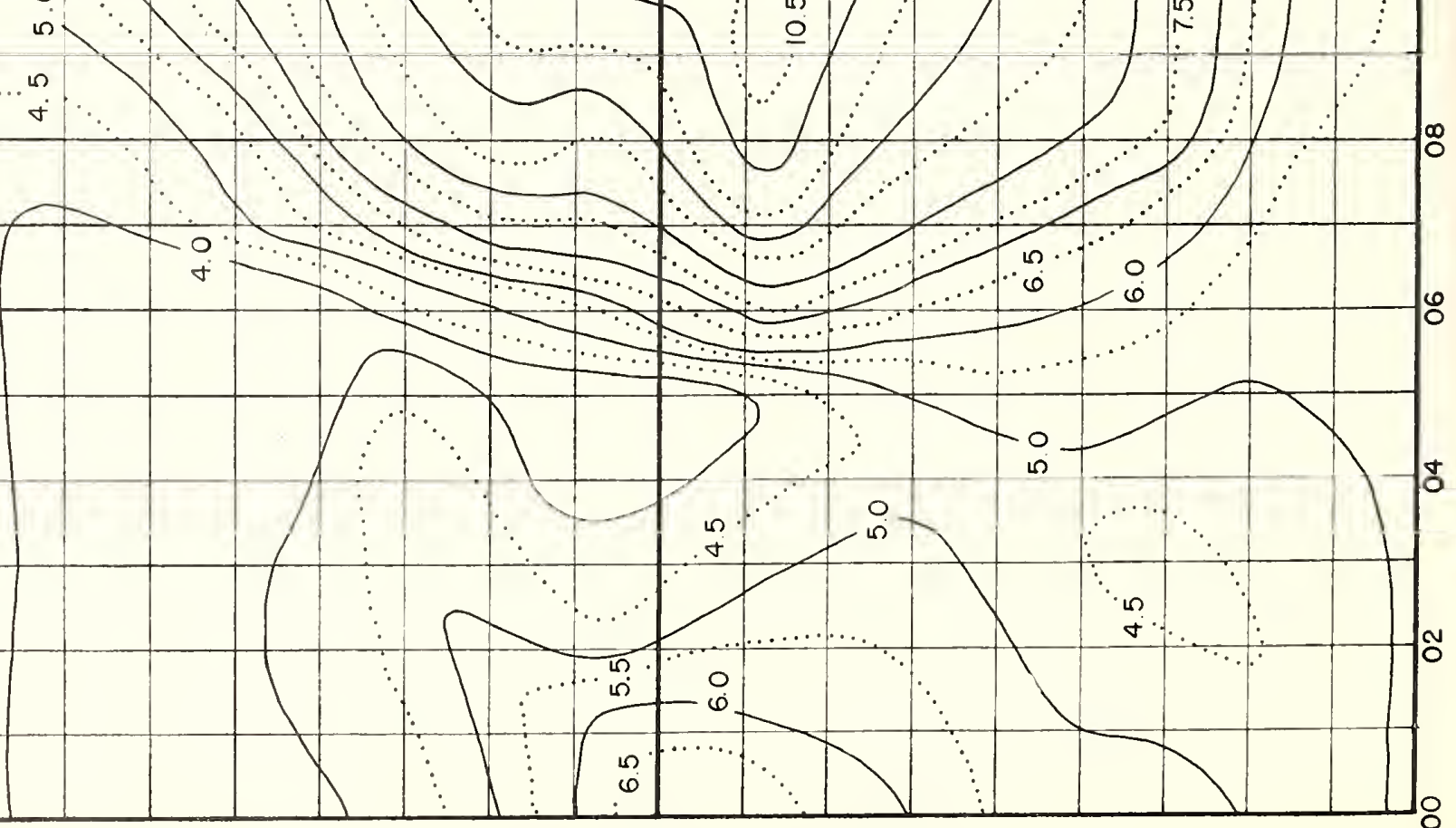

Fig. 5. F $F_{2}$ ZERO-MUF, IN Mc, W ZONE, PREDICTED FOR NOVEMBER, 1945. 


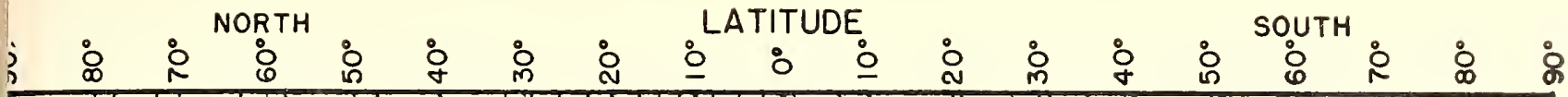



11 la $m$ m 111111

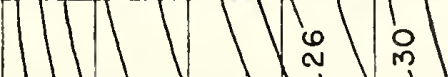

$\int \sqrt{\text { No }}$

$1+1+1$

m 10

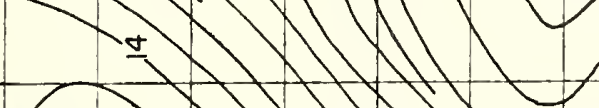

1

Fig. 6. $F_{2}$ 4000-MUF, IN Mc, W ZONE, PREDICTED FOR NOVEMBER, 1945. 


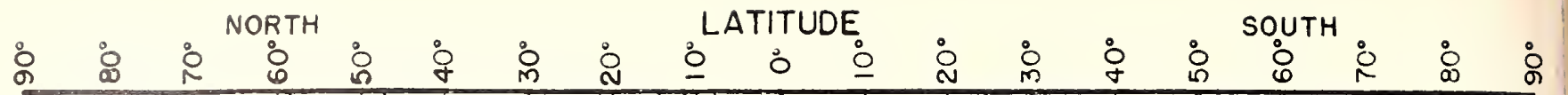

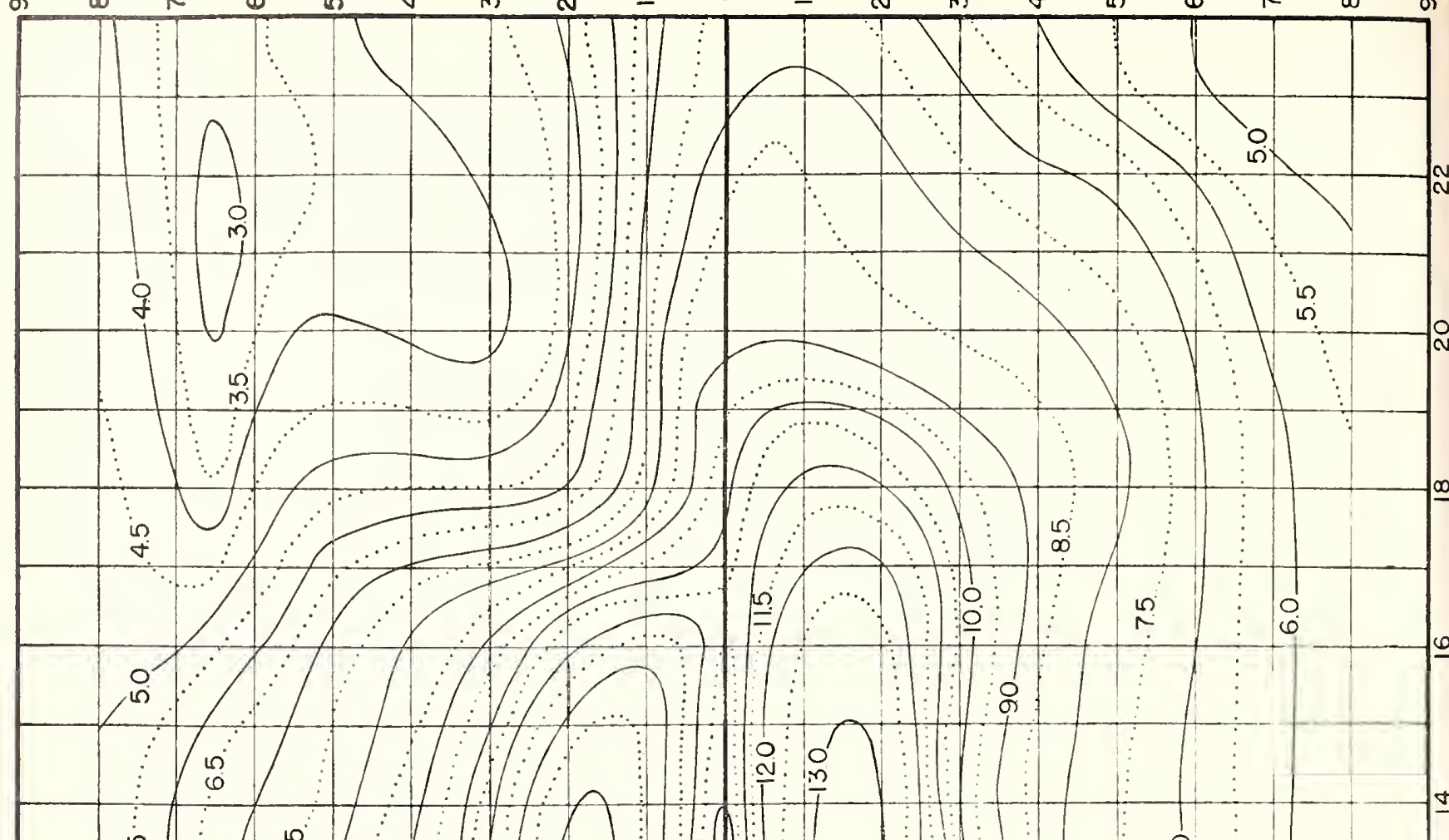

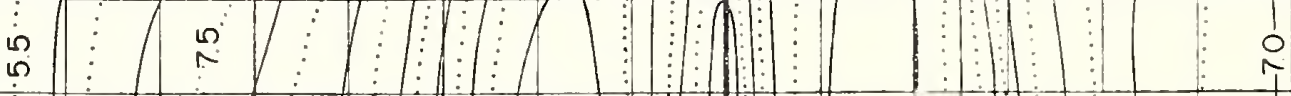

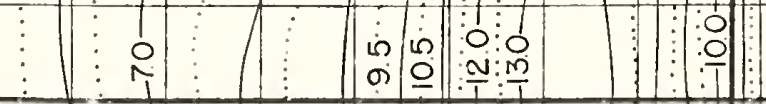

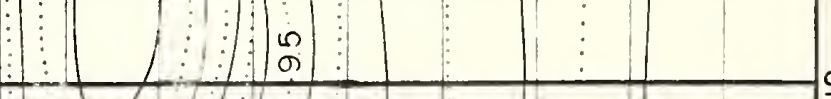

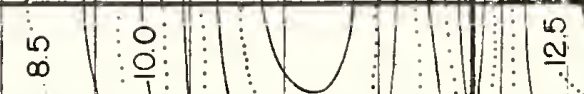

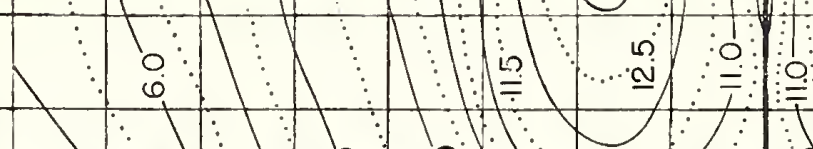

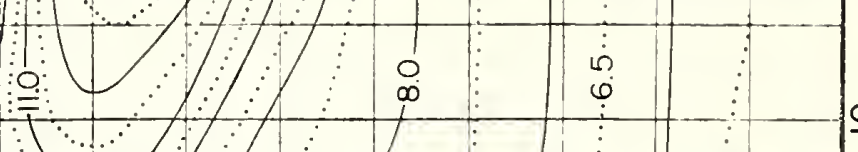

으

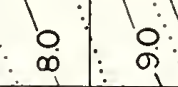
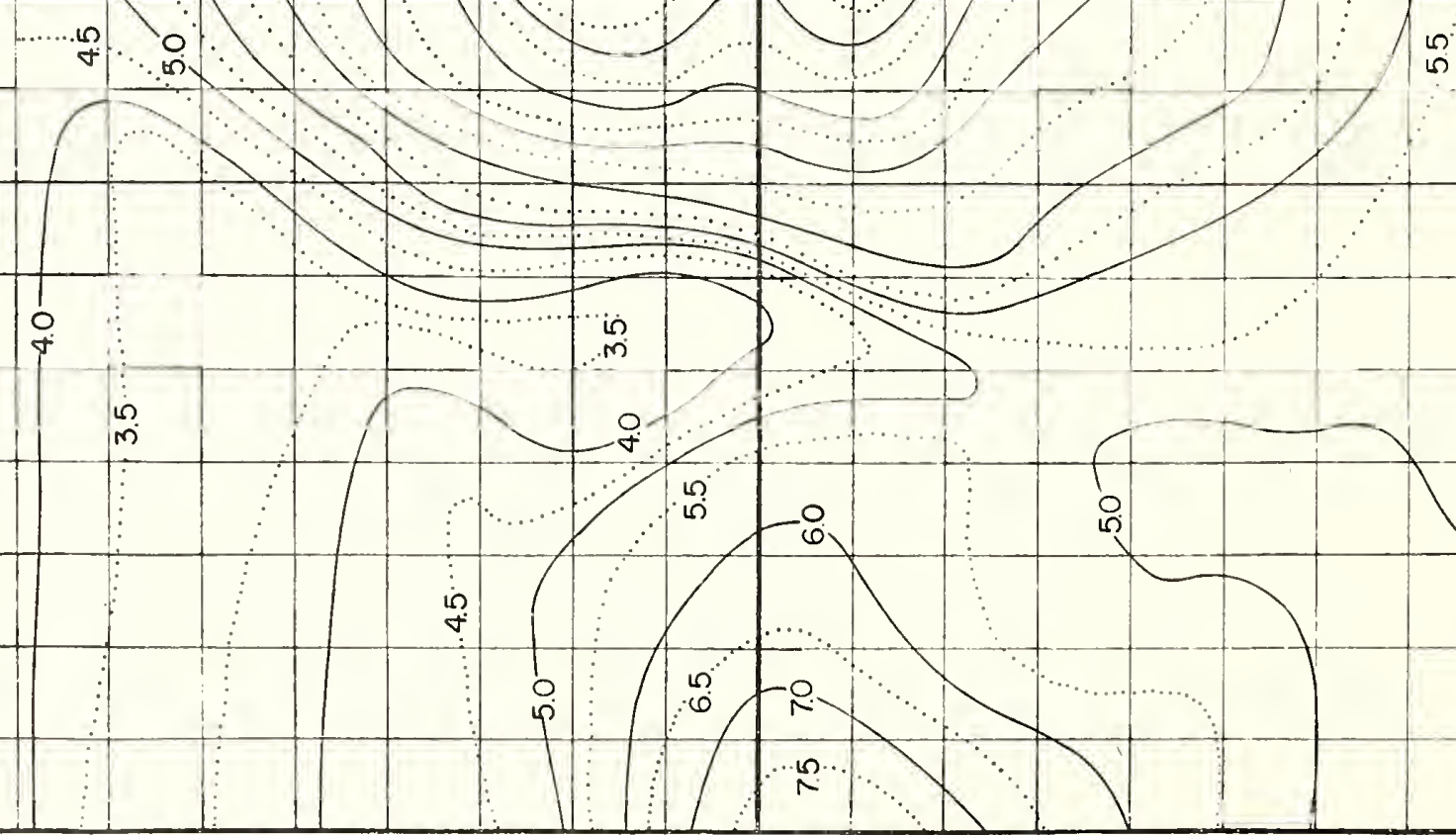

Fig 7. F 2 ZERO-MUF, IN Mc, I ZONE, PREDICTED FOR NOVEMBER, 1945. 


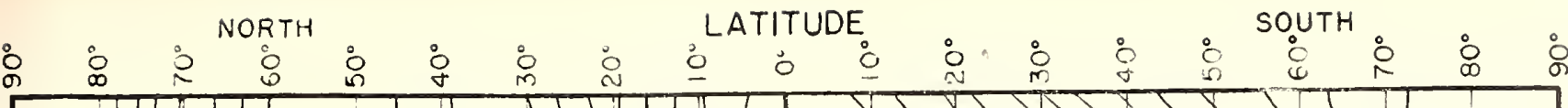

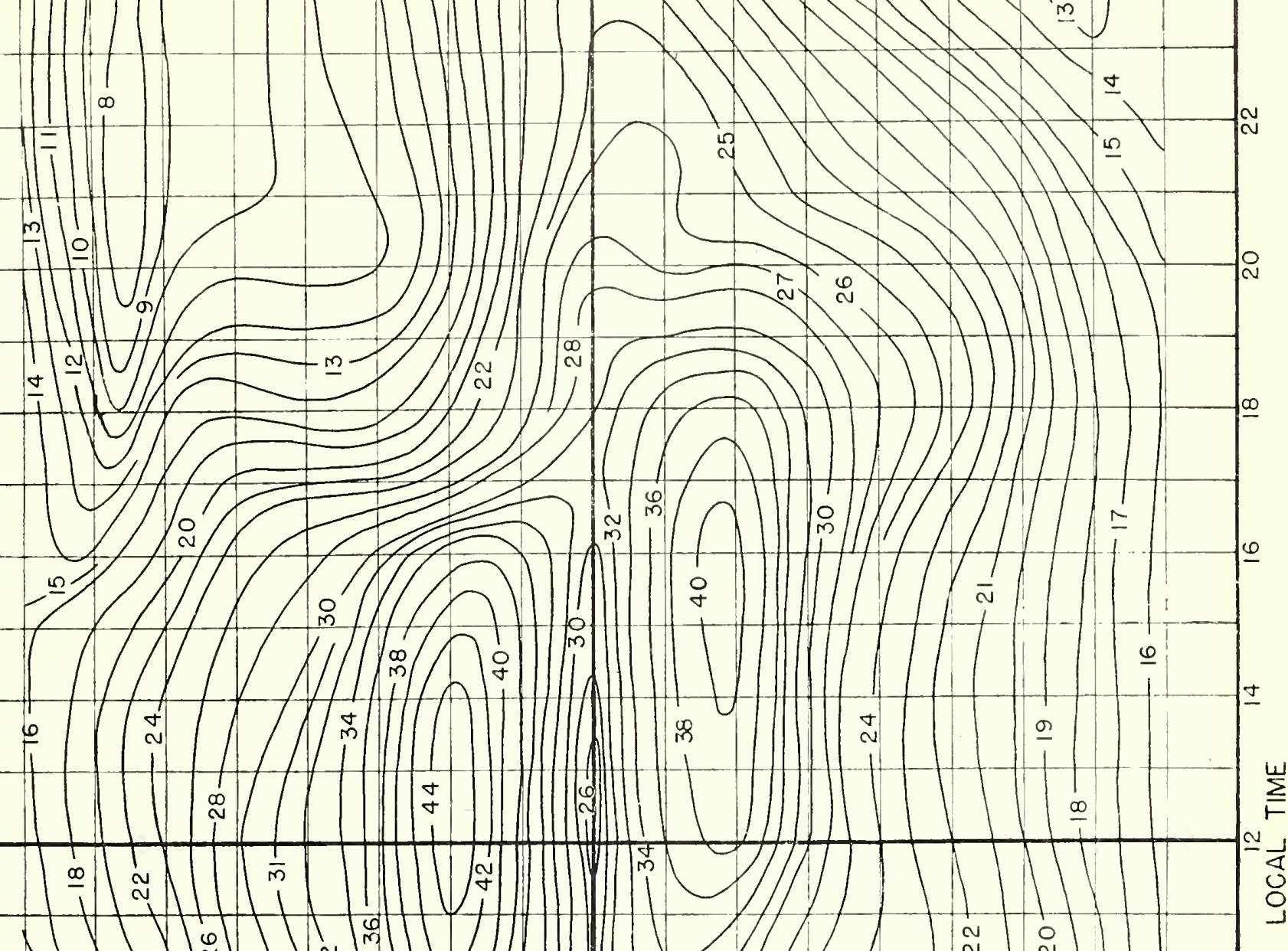

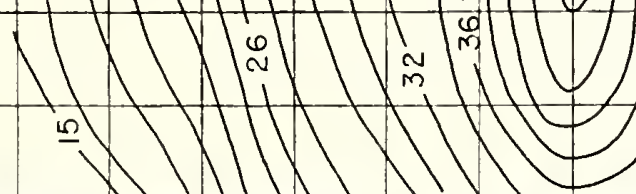
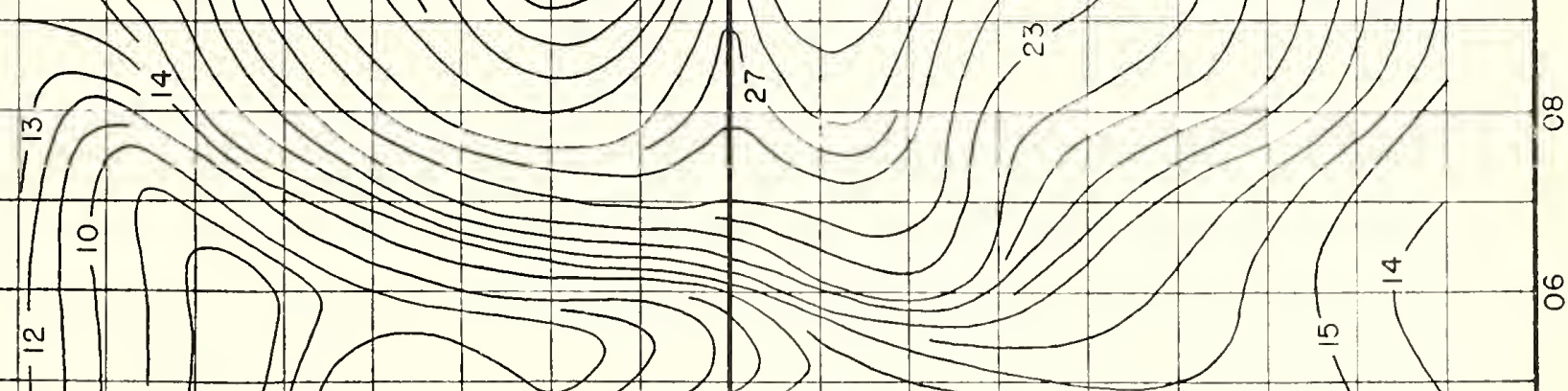

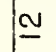

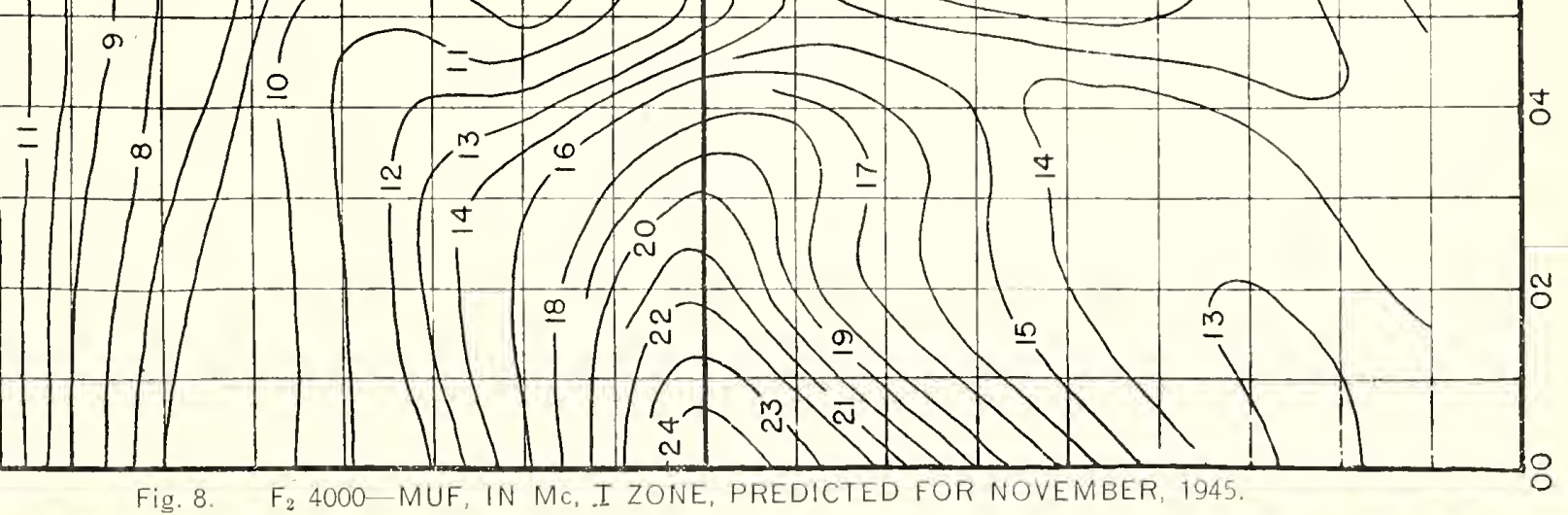




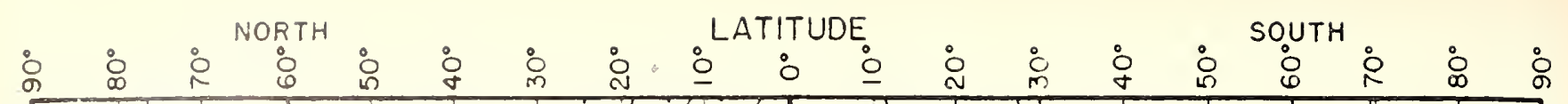

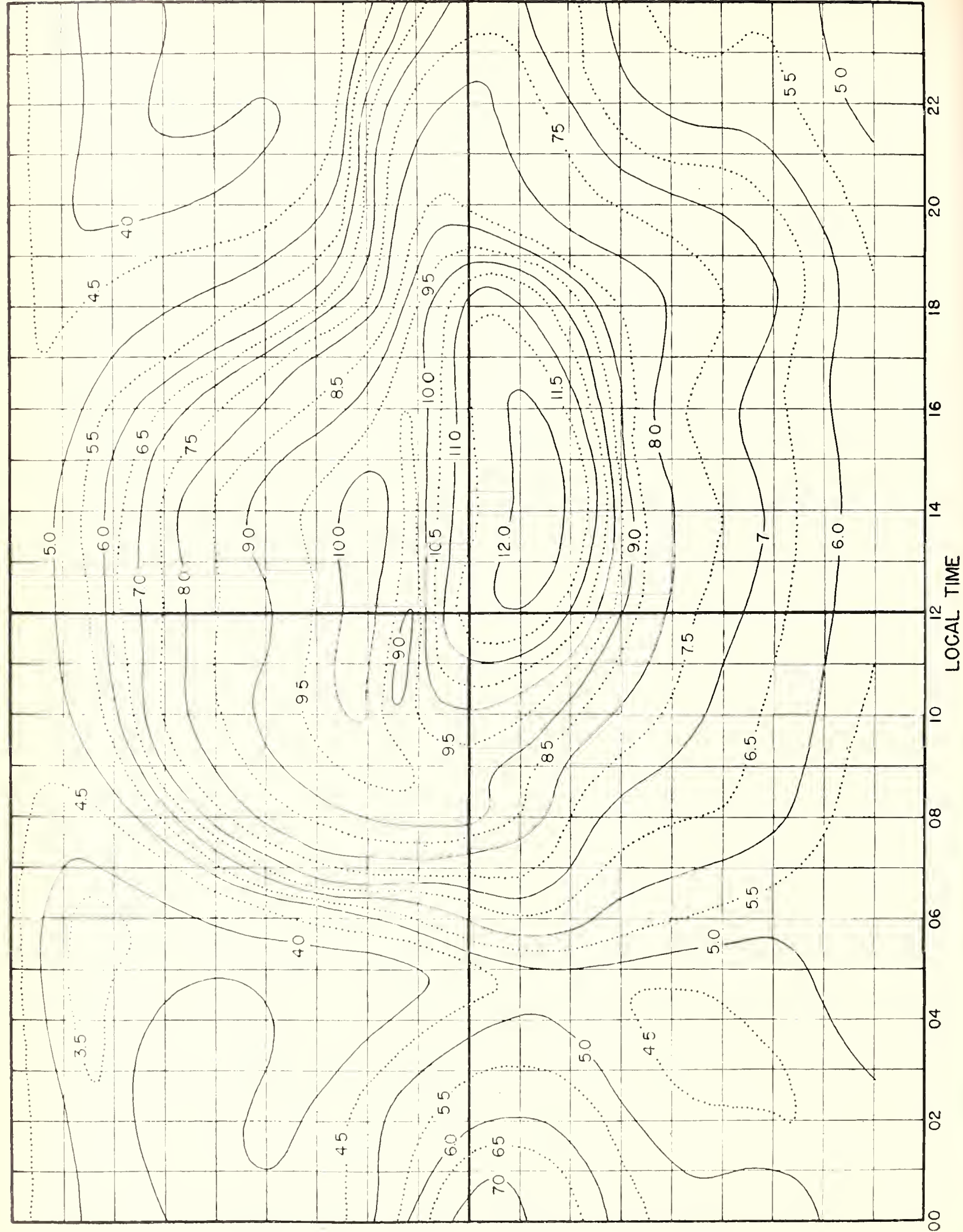

Fig. 9. $F_{2}$ ZERO-MUF, IN MC, E ZONE, PREDICTED FOR NOVEMBER, 1245. 


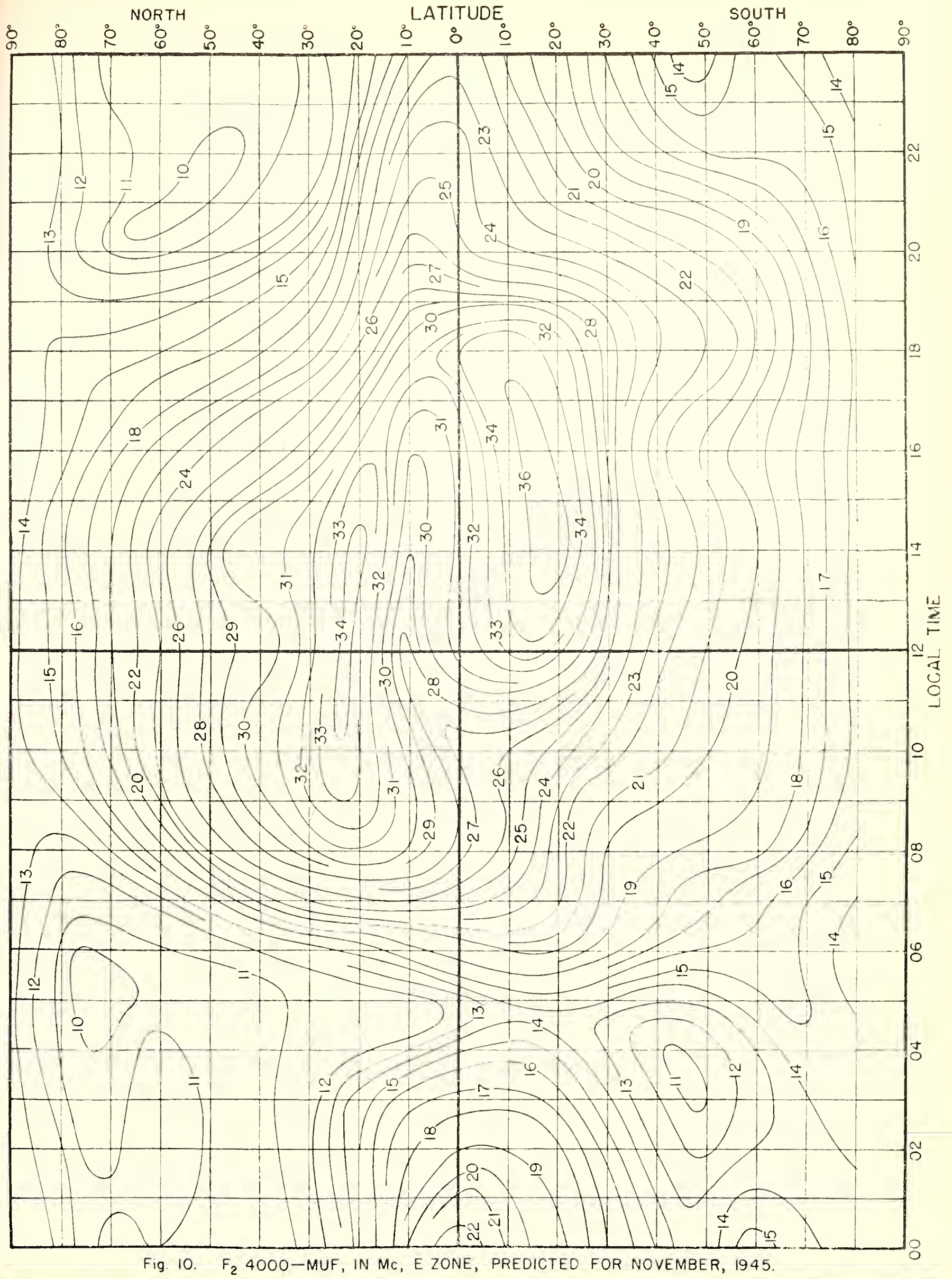




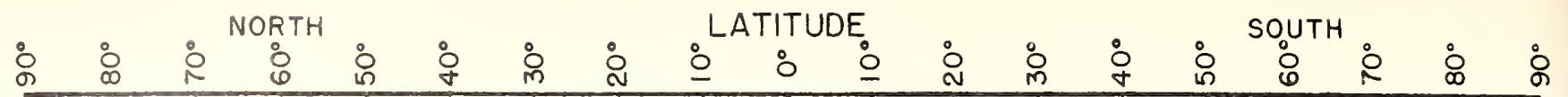

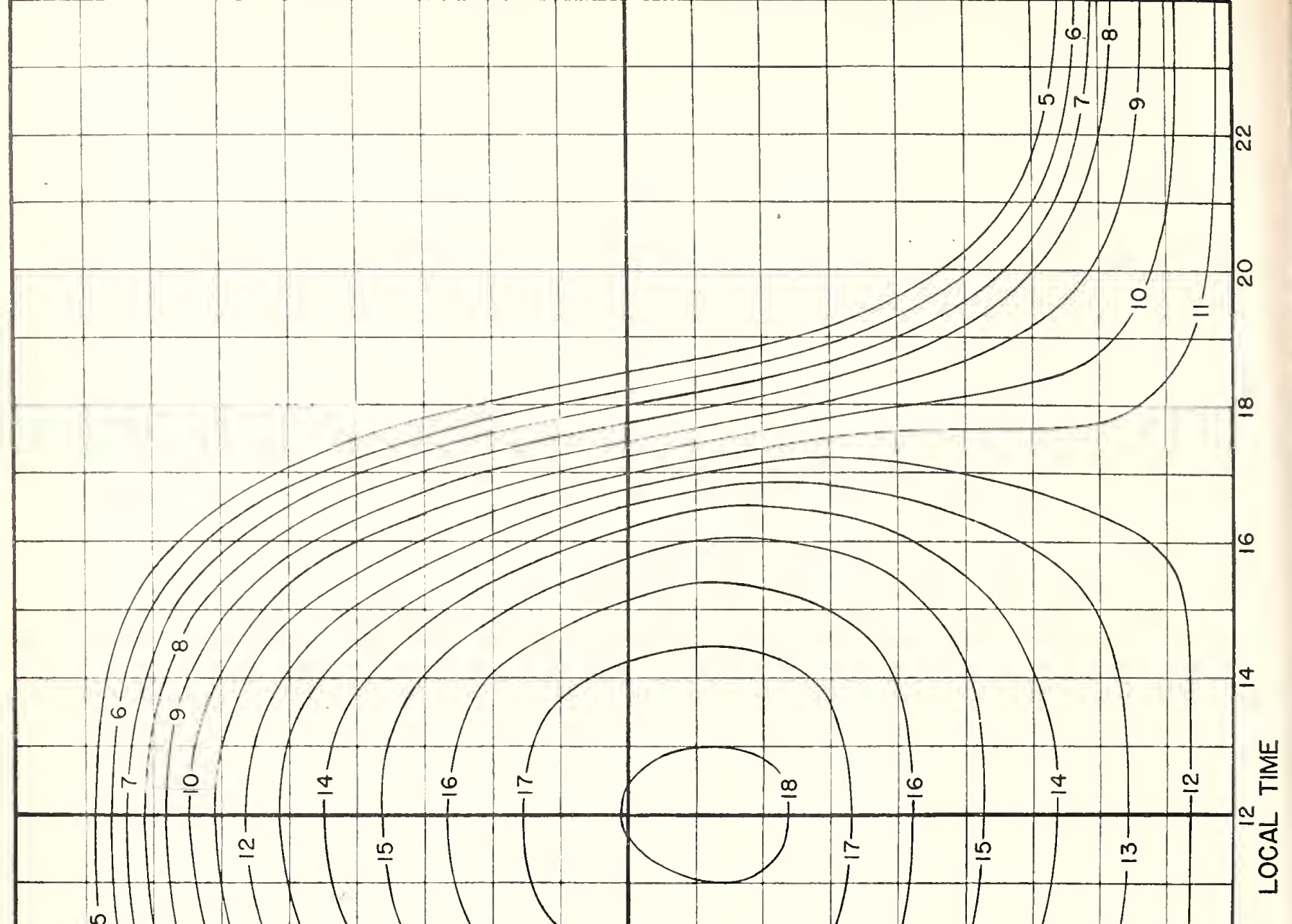

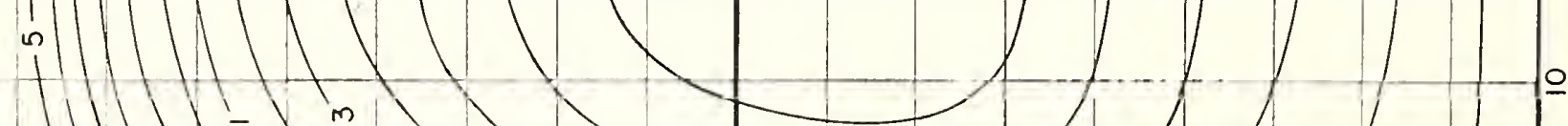

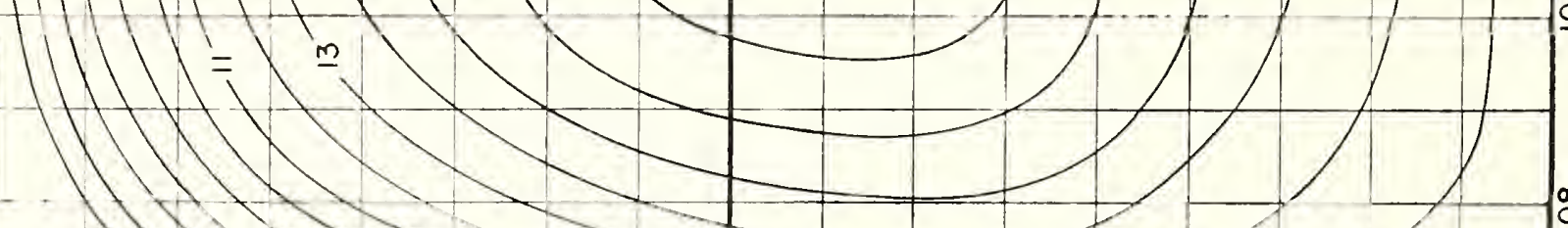




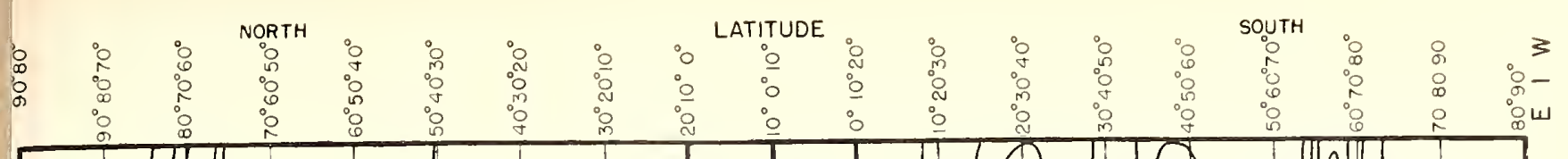
(

$(\underbrace{0}_{m}$

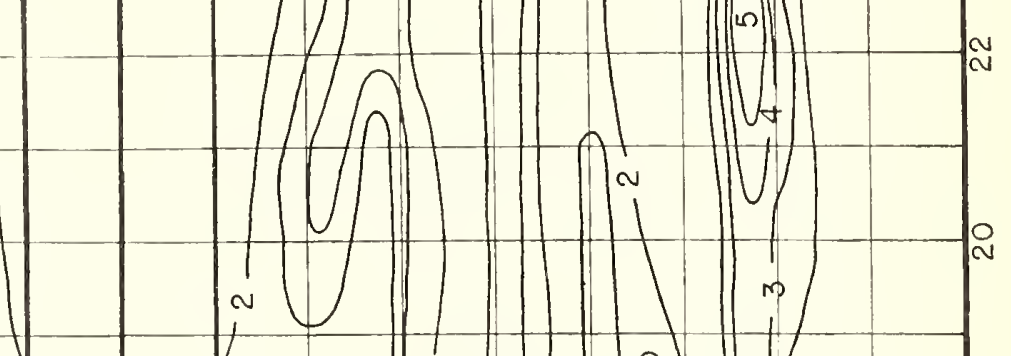




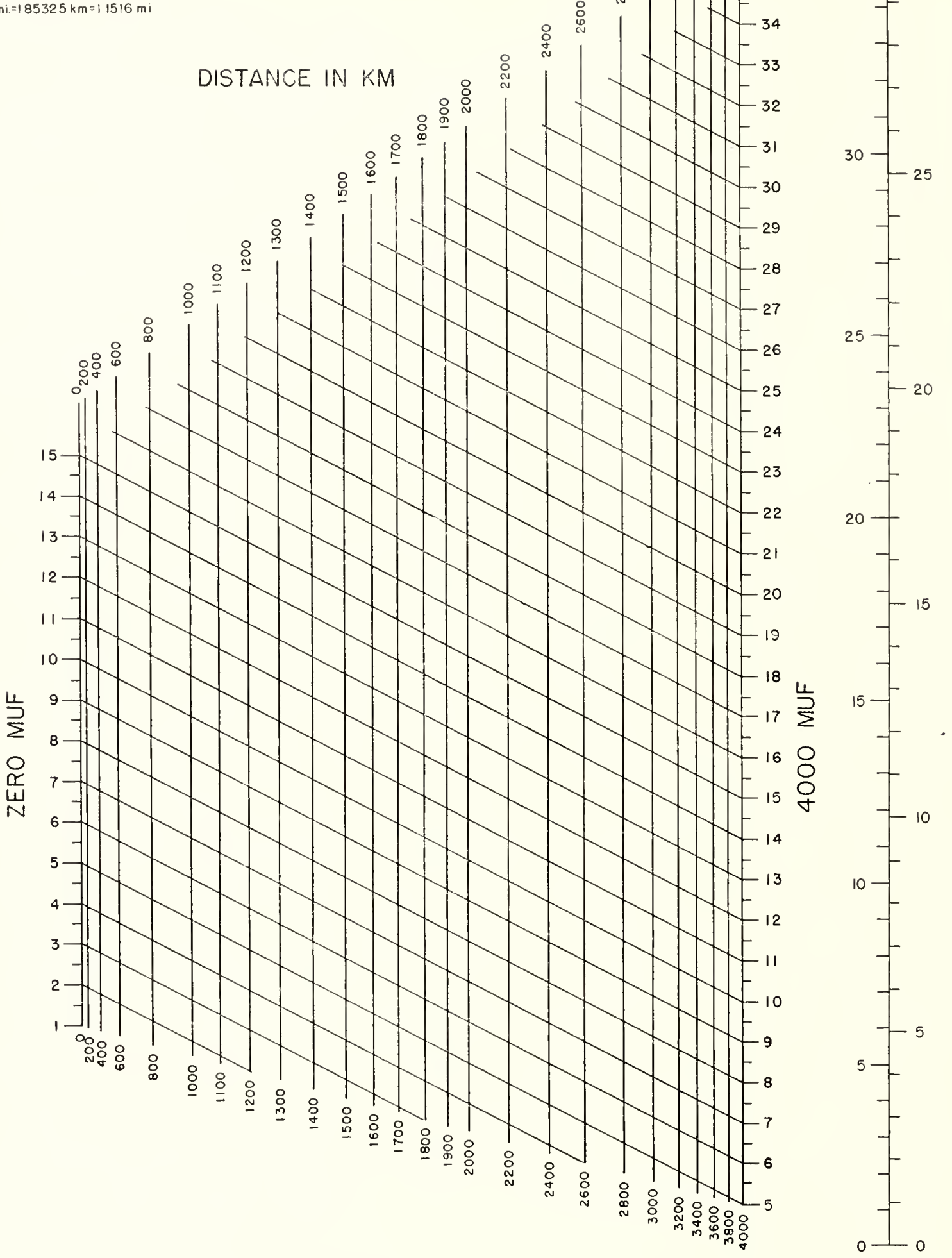

FIG.13. NOMOGRAM FOR TRANSFORIMING $F_{2}$-ZERO-MUF AND $F_{2}-4000$-MUF TO EQUIVALENT MAXIMUM USABLE FREQUENCIES AT INTERMEDIATE TRANSMISSION DISTANCES; CONVERSION SCALE FOR OBTAINING OPTIMUM WORKING FREQUENCIES. 


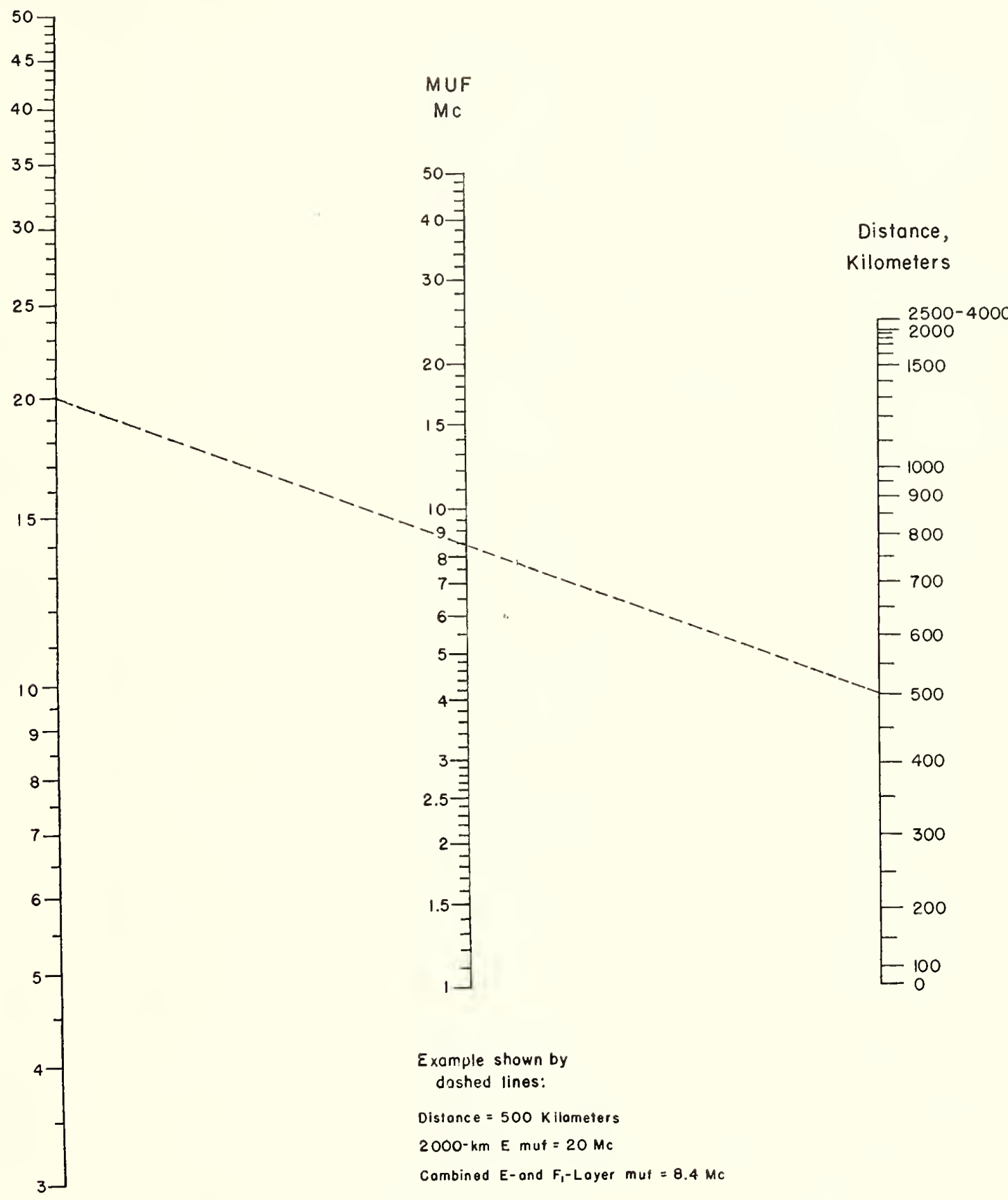

FIG. 14. NOMOGRAM FOR TRANSFORMING E-LAYER 2000-MUF TO EQUIVALENT MAXIMUM USABLE FREQUENCIES AND OPTIMUM WORKING FREQUENCIES DUE TO COMBINED EFFECT OF E LAYER AND $F_{1}$ LAYER AT OTHER TRANSMISSION DISTANCES. 


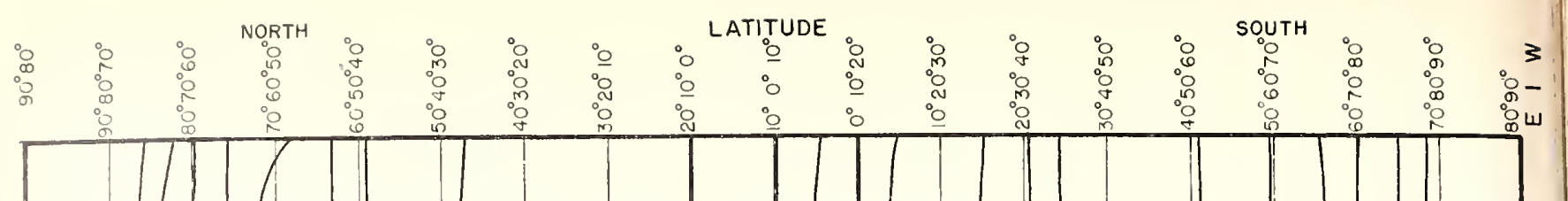

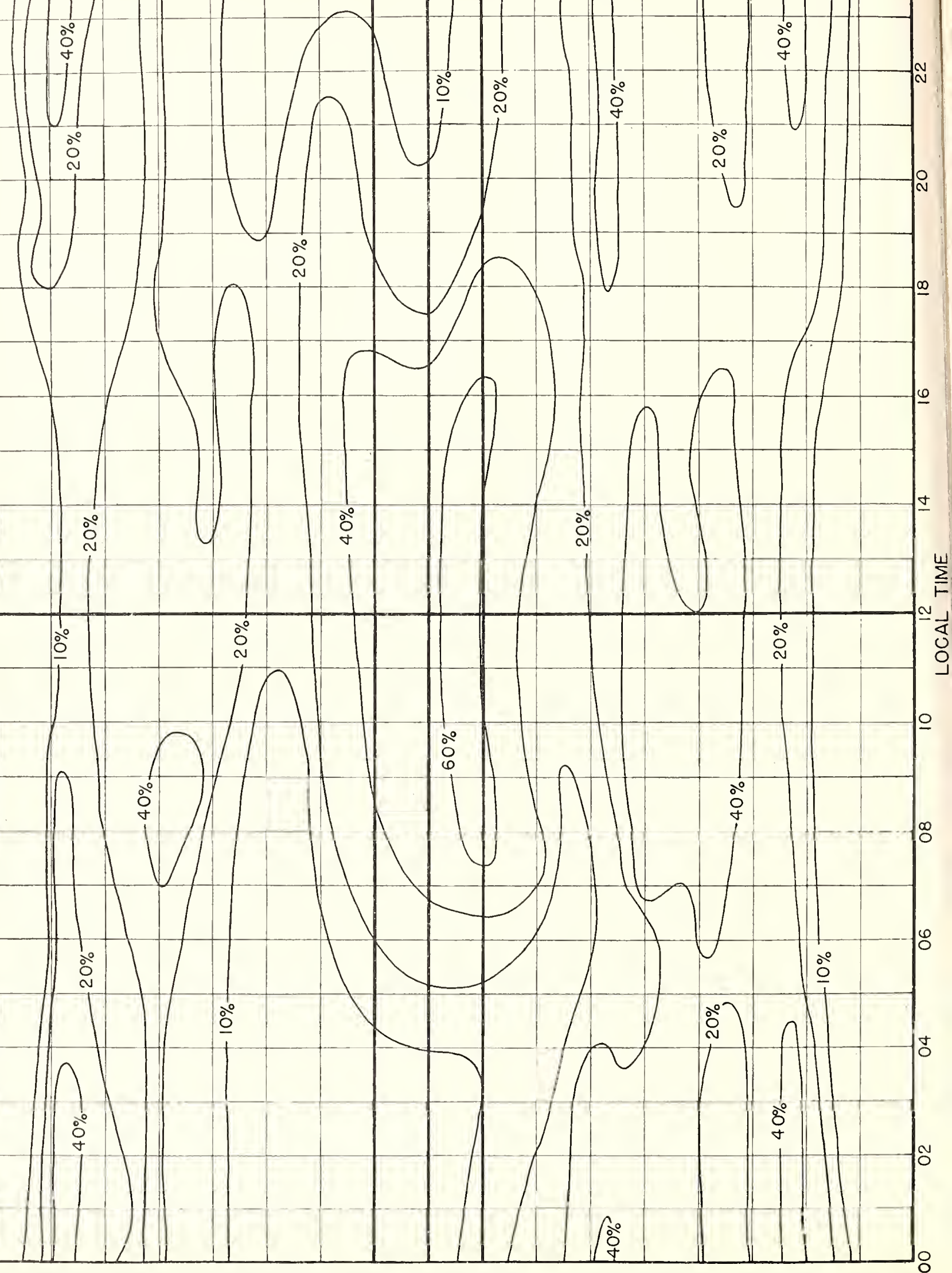

Fig. 15. PERCENTAGE OF TIME OCCURRENCE FOR ES IN EXCESS OF 15 Mc, PREDICTED FOR NOVEMBER, 1945. 

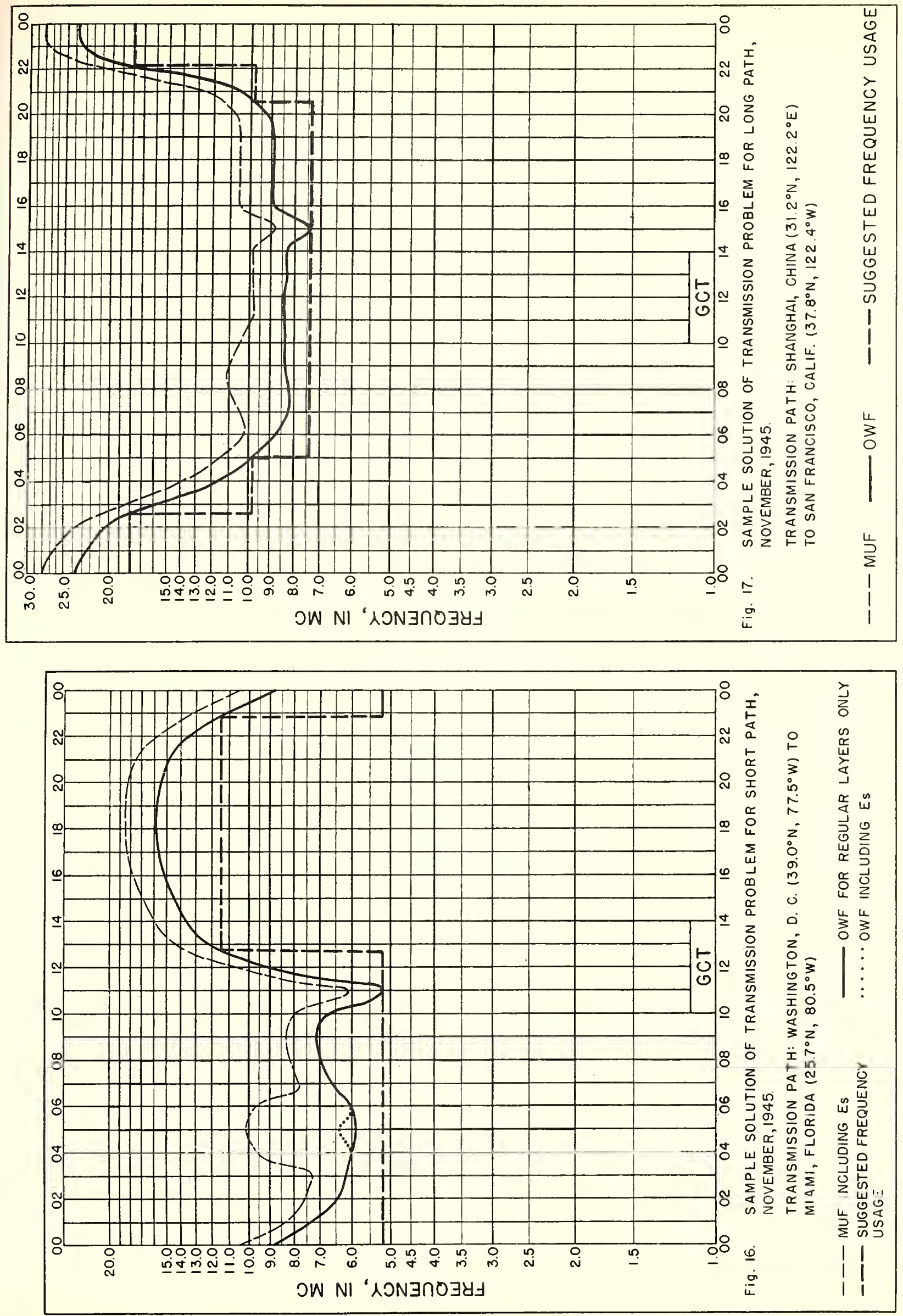



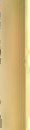




\section{IRPL REPORTS}

Daily:

Telephoned and telegraphed reports of ionospheric, solar, geomagnetic, and radio propagation data from various places.

Radio disturbance warnings.

Semiweekly:

IRPL J. Radio Propagation Forecast.

Semimonthly:

IRPL -Ja. Semimonthly Frequency Revision Factors for IRPL Basic Radio Propagation Prediction Reports. (Issued with IRPL-J series from 4 to 7 days in advance).

Monthly:

IRPL-D. Basic Radio Propagation Predictions-Three months in advance. (War Dept. TB 11-499- , monthly supplements to TM 11-499; Navy Dept. DNC-13-1（ ), monthly supplements to DNC-13-1.)

IRPL-F. Ionospheric Data.

Bimonthly:

IRPL-G. Correlation of D. F. Errors With Ionospheric Conditions.

Quarterly:

*IR PL-A. Recommended Frequency Bands for Ships and Aircraft in the Atlantic and Pacific.

IRPL-B. Recommended Frequency Bands for Submarines in the Pacific.

*IRPL-H. Frequency Guide for Operating Personnel.

**IRPL $-M$. Frequency Guide for Merchant Ships.

Special Reports, etc.:

IRPL Radio Propagation Handbook, Part 1. (War Dept. TM 11-499; Navy Dept. DNC-13-1.)

IRPL - C1 through C61. Reports and papers of the International Radio Propagation Conference, 17 April to 5 May 1944.

IRPL - R. Unscheduled reports:

R1. Maximum Usable Frequency Graph Paper.

R2 and R3. Obsolete.

R4. Methods Used by IRPL for the Prediction of Ionosphere Characteristics and Maximum Usable Frequencies.

R5. Criteria for Ionospheric Storminess.

R6. Experimental studies of ionospheric propagation as applied to a navigation system.

R7. Further studies of ionospheric propagation as applied to a navigation system.

R8. The Prediction of Usable Frequencies Over a Path of Short or Medium Length, Including the Effects of Es.

R9. An Automatic Instantaneous Indicator of Skip Distance and MUF.

R10. A method for study of the ionosphere.

R11. A Nomographic Method for Both Prediction and Observation Correlation of Ionosphere Characteristics.

R12. Ionospheric variations.

R13. Ionospheric and Radio Propagation Disturbances, October 1943 Through February 1945.

R14. A Graphical Method for Calculating Ground Reflection Coefficients.

IRPL-T. Reports on Tropospheric Propagation.

T1. Radar Operation and Weather. (Superseded by JANP 101.)

T2. Radar coverage and weather. (Superseded by JANP 102.)

-Items bearing this symbol are distributed only by U.S. Navy in NONREGISTERED PUBLICATIONS MEMORANDA (NRPM).

"Distributed only by U. S. Navy. 
